\title{
ENGINEERING DEVELOPMENT OF SLURRY BUBBLE COLUMN REACTOR (SBCR) TECHNOLOGY
}

\author{
Quarterly Technical Progress Report No. 13
}

For the Period 1 April - 30 June 1998

\section{FINAL}

\author{
Contractor \\ AIR PRODUCTS AND CHEMICALS, INC. \\ 7201 Hamilton Blvd. \\ Allentown, PA 18195-1501 \\ Bernard A. Toseland, Ph.D. \\ Program Manager and Principal Investigator \\ Robert M. Kornosky \\ Contracting Officer's Representative
}

Prepared for the United States Department of Energy

Under Cooperative Agreement No. DE-FC22-95PC95051

Contract Period 3 April 1995 - 2 April 2000

\section{NOTE: AIR PRODUCTS DOES NOT CONSIDER ANYTHING IN THIS REPORT TO BE CONFIDENTIAL OR PATENTABLE.}




\title{
ENGINEERING DEVELOPMENT OF SLURRY BUBBLE COLUMN REACTOR (SBCR) TECHNOLOGY
}

\author{
Quarterly Technical Progress Report No. 13 \\ For the Period 1 April - 30 June 1998
}

\section{Contract Objectives}

The major technical objectives of this program are threefold: 1) to develop the design tools and a fundamental understanding of the fluid dynamics of a slurry bubble column rector to maximize reactor productivity, 2) to develop the mathematical reactor design models and gain an understanding of the hydrodynamic fundamentals under industrially relevant process conditions, and 3) to develop an understanding of the hydrodynamics and their interaction with the chemistries occurring in the bubble column reactor. Successful completion of these objectives will permit more efficient usage of the reactor column and tighter design criteria, increase overall reactor efficiency, and ensure a design that leads to stable reactor behavior when scaling up to large diameter reactors.

\section{Summary of Progress}

\section{Task 2: Component Diagnostics Development} Bubble Size Measurement

An optical fiber probe was developed to measure the initial bubble size from a single nozzle and bubbling-jetting transition in liquid-solid suspensions. This work uses the previously developed bubble size probe to provide information on bubble formation. It will be extended to study liquid-solid systems, as well as gas-liquid systems.

(The Ohio State University)

\section{Task 3: Model Selection and Development Estimation of Eddy Diffusivities}

A method for estimating turbulent eddy diffusivities was developed using the existing database for scaleup and design of bubble columns. This was implemented by using the cross-sectional averaged axial and radial turbulent eddy diffusivities calculated from the Computer Automated Radioactive Particle Tracking (CARPT) measurements in air-water in three column sizes $(14,19$, and $44 \mathrm{~cm}$ diameters). The correlations were then developed by generalizing these methods. These correlations represent a preliminary attempt to describe the effects of scale and superficial gas velocities on the turbulent diffusivities because of the limited amount of data. 


\section{Column Design}

The scaleup procedures for the gas holdup and liquid recirculating velocity which were developed previously (see the January - March 1998 quarterly report), along with the newly developed eddy diffusivities estimation procedure can be useful as design tools. A methodology has been proposed to estimate the mean liquid recirculation velocity and the turbulent eddy diffusivities for systems of industrial interest from more easily obtained laboratory data taken in air-water systems. This is a preliminary effort, and more data are needed. As discussed below (Task 6), this methodology has been used successfully in interpreting tracer data from the Alternative Fuels Development Unit (AFDU). This application provides at least indirect verification of the methodology.

(Washington University in St. Louis)

\section{Task 4: SBCR Experimental Program Initial Bubble Formation}

Bubbles drive the flow in bubble columns. It is quite likely that flow conditions are determined, in part, by the way in which bubbles are formed. This effect is strong in the region of the column before flow is fully developed and at moderate gas flow rates. Although there is much work describing bubble formation, there is little work at high pressures and less involving the presence of solids. The newly developed optical probe was used to study the effects of particles and pressure on bubble formation in liquid-solid suspensions.

1. The particles have a significant effect on the initial bubble size and motion of bubbles. At identical operating conditions, the bubbles formed in the liquid-solid suspensions are larger than those in the liquid-only suspensions. The bubble size increases with an increase in solids holdup.

2. The effect of pressure on the initial bubble size was studied for the constant flow regime and was found to be insignificant for this condition. Standard analysis of bubble formation identifies three different flow regimes: constant flow, intermediate and constant pressure. The effect of pressure could be significantly different in each regime. The constant pressure regime is generally the condition of industrial importance. We plan to measure the effect of pressure in the constant pressure regime in the next quarter.

(The Ohio State University)

\section{Task 6: Data Processing}

\section{Prediction of Mixing Times from Tracer Studies}

As discussed in previous reports, a fundamental, two-dimensional convectiondiffusion model has been developed. This model has been used to interpret the liquid-phase tracer data taken at the LaPorte AFDU during methanol 
synthesis. The model parameters were obtained, based on the new scaleup methodology (see Task 3). Since CARPT measurements on air-water systems at atmospheric pressure and the estimated radial gas holdup profile at LaPorte were used to estimate parameters from laboratory data, the methodology allows calculation of flow characteristics for industrial situations from laboratory data.

The gas holdup profile at LaPorte was estimated from the Nuclear Gauge Densitometry and the pressure drop measurements taken during the run. The model can provide an estimate of the internal liquid mixing in bubble columns. The values of mixing time for the AFDU were estimated from the model using the new methodology. The mixing times were also inferred from tracer measurements during the trial. The values agree well. Thus, we conclude that this scaleup procedure results in fairly good predictions of the characteristic mixing times within the column, as measured by the radiation detectors at various axial locations. This provides an indirect verification of the model.

(Washington University)

\section{Turbulence Parameters}

Analysis of laboratory data for two subjects has been completed. The findings from both these studies will be organized in a report format for the next quarterly report. The two areas are:

1. estimation of the liquid phase turbulent mixing length from CARPT and CT measurements for use in CFD (Computational Fluid Dynamics) simulations of flows in bubble columns. (An estimate of mixing length is needed for the simplest closures for turbulence models used in most CFD solvers, such as the CFDLIB code developed at Los Alamos.)

2. comparison of time-averaged liquid/slurry "turbulent" parameters in gasliquid and gas-liquid-solid slurry bubble columns.

(Washington University) 


\title{
The Ohio State University Research
}

The report from Ohio State University for the period follows:

\section{INTRINSIC FLOW BEHAVIOR IN A SLURRY BUBBLE COLUMN UNDER HIGH PRESSURE AND HIGH TEMPERATURE CONDITIONS}

\author{
Quarterly Report
}

(Reporting Period: April 1 to June 30, 1998)

\section{Highlights}

- An optical fiber probe was developed to measure the initial bubble size from a single nozzle and bubbling-jetting transition in liquid-solid suspensions. The signals of light intensity from the probe were analyzed to study the bubblingjetting transition.

- The effects of particle and pressure on bubble formation in liquid-solid suspensions were studied. The presence of particles in liquid had a significant effect on the initial bubble size and motion of bubbles. At identical operating conditions, the bubbles formed in the liquid-solid suspensions were larger than those in the liquid. The bubble size increased with an increase in solids holdup.

- The effect of pressure on the initial bubble size may vary significantly with bubble formation conditions dictated by constant flow condition, intermediate condition and constant pressure condition. In this work, the bubble formation was under the constant flow condition. It was found that the effect of pressure on initial bubble size was insignificant for the constant flow condition.

\section{Work Conducted}

\section{Measurement of Initial Bubble Size and Bubbling-Jetting Transition}

The optical fiber probe system discussed in the previous monthly report was used for the detection of bubbles or jets in liquid-solid suspensions at high pressures.

To establish objective criteria for the bubbling-jetting transition in liquid-solid suspensions, experiments were first performed in a liquid system over a wide range of orifice Reynolds numbers $\left(\operatorname{Re}_{\mathrm{o}, \mathrm{g}}=\rho_{\mathrm{g}} \mathrm{d}_{0} \mathrm{u}_{0} / \mu_{\mathrm{g}}\right)$. Figure 1 shows a series of photographs of the gas flow through the orifice at various $\operatorname{Re}_{\mathrm{o}, \mathrm{g}}$. At $\operatorname{Re}_{\mathrm{o}, \mathrm{g}}=1,075$ (case E1), single bubbles are formed from the orifice. With increasing $\operatorname{Re}_{\mathrm{o}, \mathrm{g}}$ to 5,321 (case $\mathrm{E} 2$ ), 
bubbles being formed at the orifice start to interact with the preceding ones. Bubble coalescence occurs between the two bubbles, sometimes involving more bubbles. In case E3 $\left(\operatorname{Re}_{\mathrm{o}, \mathrm{g}}=8,809\right)$, frequent coalescence of successive bubbles is observed. A jet-like gas plume appears in the photo, which rarely breaks up near the orifice. Case E3 marks the beginning of the bubbling-jetting transition. In cases E4, E5, and E6, it is clear from the photos that the flow is in the jetting regime. Bubbles of various sizes break away from the top of the jets in this regime. It can also be seen that the jet penetration depth increases with an increase in $\mathrm{Re}_{\mathrm{o}, \mathrm{g}}$.

The signals of light intensity from the probe corresponding to cases E1, E2, E3, and E6 are shown in Figure 2(a), along with their power spectra [Fig. 2(b)]. The signal for E1 shows sharp and discrete peaks in time domain. The shape of the peaks is regular, and the height and width of the peaks are uniform. Distinct peaks also appear in frequency domain, with the bubbling frequency equal to the dominant frequency. When bubble interactions start (E2), most apparent peaks in the signal include several auxiliary peaks, corresponding to interacting bubbles. Most peaks in this case are regular in shape, height, and width, although some irregular peaks appear, which induce the widening of the frequency spectrum. However, the range of the dominant frequencies is still relatively narrow. The signal for E3 loses almost all the regularities in shape, height, and width of the peaks. The corresponding power spectrum also shows a wide distribution of dominant frequencies. All these characteristics signify the formation of jetting. The characteristics of the signals are similar once the flow is under the jetting condition, i.e., irregular in shape, height, and width of the peaks in the signal and a wide range of dominant frequencies or disappearance of dominant frequencies, as in case E6.

\section{Effect of Particles on Initial Bubble Size in Liquid-Solid Suspensions}

For high-pressure systems, some studies in the literature examine the initial bubble size in liquids, but little is known about the initial bubble size in the presence of particles. However, a reasonable estimation of the initial bubble size is important for the design of slurry bubble column reactors in which catalytic particles are present.

Our experiments found that the presence of particles in liquid has a significant effect on the motion of bubbles. Flow visualization of bubble formation in the liquid, with or without continuous liquid flow, reveals that all the bubbles follow the same trajectory. Once the probe is properly aligned with the orifice, the trajectory of the bubbles intercepts the tip of the probe, yielding consecutive steady peaks in the light intensity signals in the bubbling regime. However, the bubbles in liquid-solid suspensions have varied trajectories. The probe can only detect bubbles periodically. Flow visualization also confirms that the bubbles emerge from the bed surface at different locations. The unsteady bubble trajectories in liquid-solid suspensions are due to the heterogeneous nature of the suspension. 
Figure 3 shows the effect of particles on the initial bubble size. The bubble size is obtained at the same distance above the orifice in the liquid and the liquid-solid suspension. Various solids holdups in the suspension are obtained by varying the fluidizing liquid velocity. The fluidizing liquid velocity is so small that the superficial liquid flow does not significantly alter the bubble formation behavior. At both ambient and 4.2 MPa pressures, the bubbles formed in the liquid-solid suspension are larger than those formed in the liquid for a given $\mathrm{u}_{0}$. The bubble size increases with an increase in solids holdup. The experimental data of Massimilla et al. (1961) showed a similar trend. The experimental data shown in the figure clearly indicate that models or correlations obtained in liquid will significantly underestimate the initial bubble size in liquid-solid media.

\section{Effect of Pressure on Initial Bubble Size in Liquid-Solid Suspensions}

Numerous experimental and modeling studies have been conducted over the past decades on bubble formation from a single orifice or nozzle submerged in liquids, mostly under ambient conditions. Only a few studies were conducted at elevated pressures. The high-pressure studies indicate that an increase in gas density reduces the size of bubbles formed from single orifices. However, these results were limited to water systems only. The effect of pressure on the initial bubble size in hydrocarbon liquids systems is not understood. Furthermore, it is known that the volume of the gas chamber connected to the nozzle is an important factor in determining the initial bubble size. Clearly, the effect of pressure on initial bubble size may vary significantly with the bubble formation conditions dictated by three conditions, i.e., constant flow, intermediate and constant pressure conditions. In this work, the volume of the gas chamber is zero and the bubble formation can be considered as under constant flow conditions.

Our work shows that the effect of pressure on initial bubble size is insignificant in the liquid-solid suspension, as well as in the liquid (as shown in Fig. 4), under constant flow conditions. Increasing pressure does not significantly change the bubble sizes for a given solids holdup, orifice gas velocity, and temperature.

It is well known that the initial bubble size is determined based on the balance among various forces acting on the bubble formed at the nozzle. In a liquid, the upward forces include buoyancy and gas momentum forces; the downward forces include liquid drag, surface tension, bubble inertial force, and Basset forces. The presence of particles induces two additional downward forces on the bubble: particle-bubble collision force and liquid-solid suspension inertial force. The increase in the particlebubble collision force and liquid-solid suspension inertial force with increasing solids holdup leads to an increased initial bubble size. Considering all the forces, a mathematical model has been developed to quantify the initial bubble size in liquidsolids suspensions. The model will be described in future monthly reports. This model reveals that for the current experimental system, the effect of pressure on the 
overall upward forces and overall downward forces is comparable, leading to an insignificant net effect of pressure on the initial bubble size.

\section{Reference}

Massimilla, L., A. Solimando, and E. Squillace, British Chemical Engineering, April, 233 (1961). 


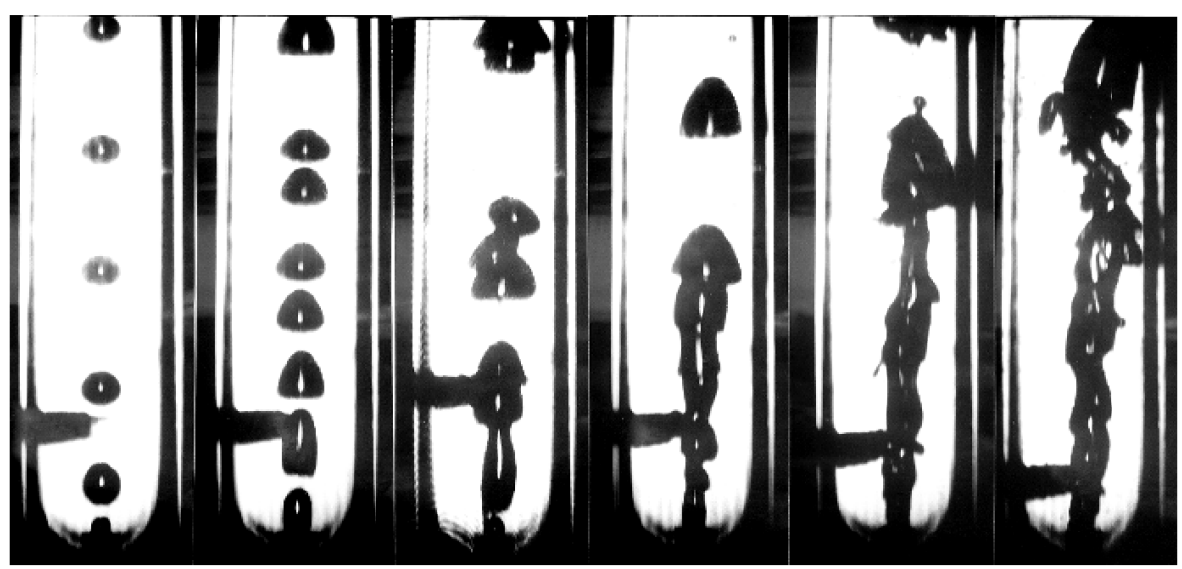
(a) E1
(b) E2
(c) E3
(d) E4
(e) E5
(f) E6

Figure 1. A series of photographs showing the bubbling-jetting transition $(\mathbf{P}=$ 4.24 MPa, $\mathrm{T}=28^{\circ} \mathrm{C}$ ). (a) E1: $\mathrm{u}_{0}=$ $0.27 \mathrm{~m} / \mathrm{s}, R_{\mathrm{o}, \mathrm{g}}=1075$; (b) E2: $\mathrm{u}_{0}$ $=1.35 \mathrm{~m} / \mathrm{s}, \operatorname{Re}_{\mathrm{o}, \mathrm{g}}=5321$; (c) $\mathrm{E3}$ : $u_{0}=2.23 \mathrm{~m} / \mathrm{s}, \operatorname{Re}_{o, g}=8809$; (d) $\mathrm{E} 4: \mathbf{u}_{0}=2.60 \mathrm{~m} / \mathrm{s}, \operatorname{Re}_{\mathrm{o}, \mathrm{g}}=10243$;

(e) E5: $\mathbf{u}_{0}=3.99 \mathrm{~m} / \mathrm{s}, \operatorname{Re}_{0, \mathrm{~g}}=$ 15759; (f) E6: $u_{0}=6.42 \mathrm{~m} / \mathrm{s}, \operatorname{Re}_{o, g}$ $=25355$. 


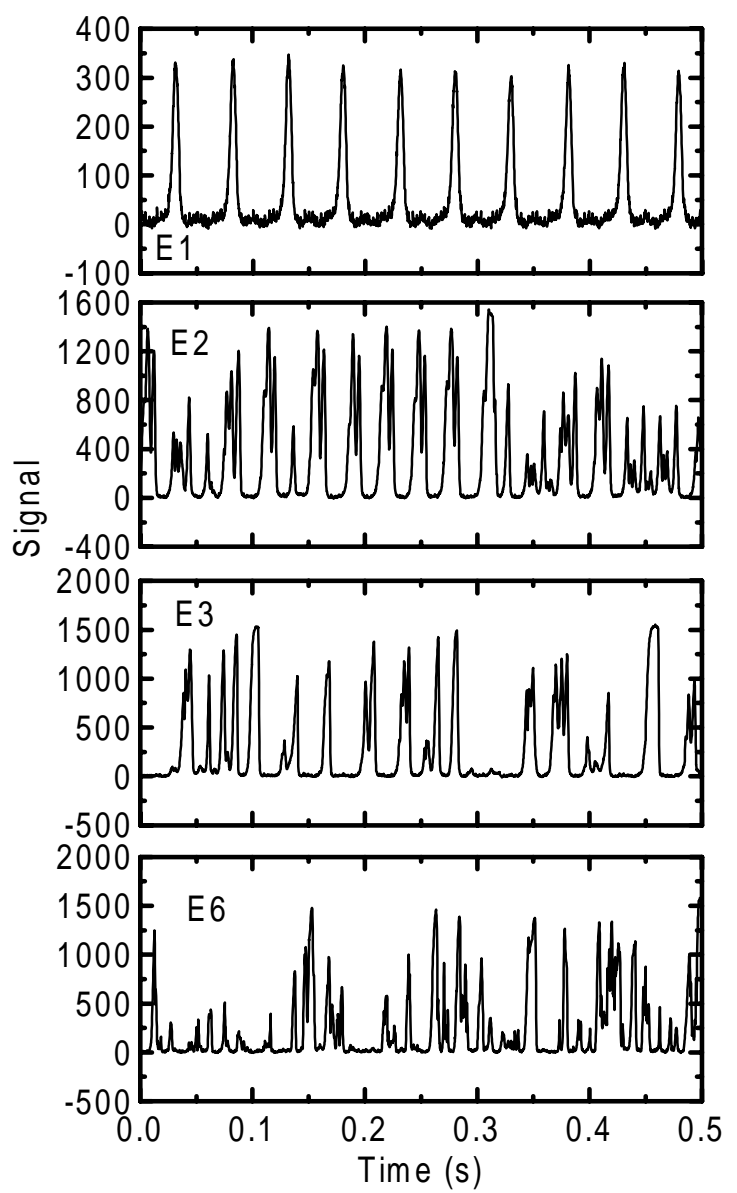

(a)

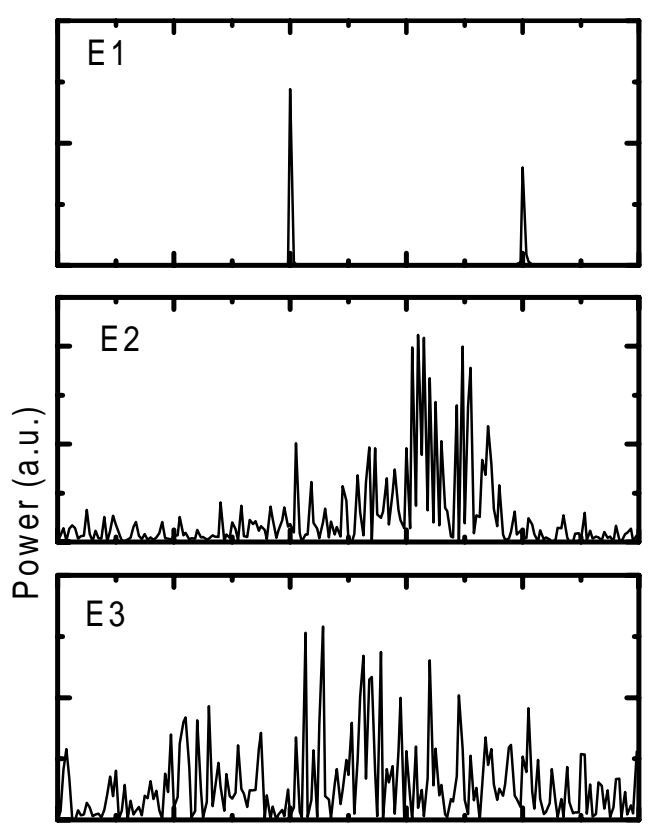

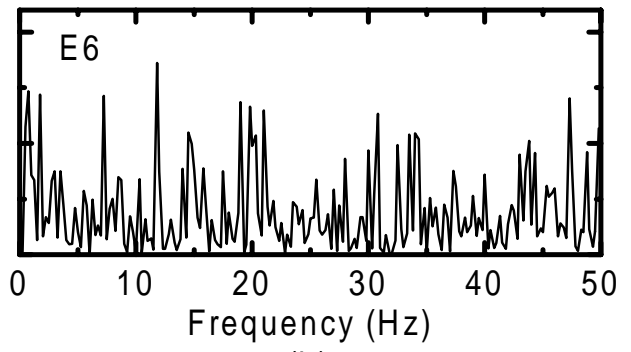

(b)

Figure 2. (a) Typical signals and (b) corresponding power spectra. 

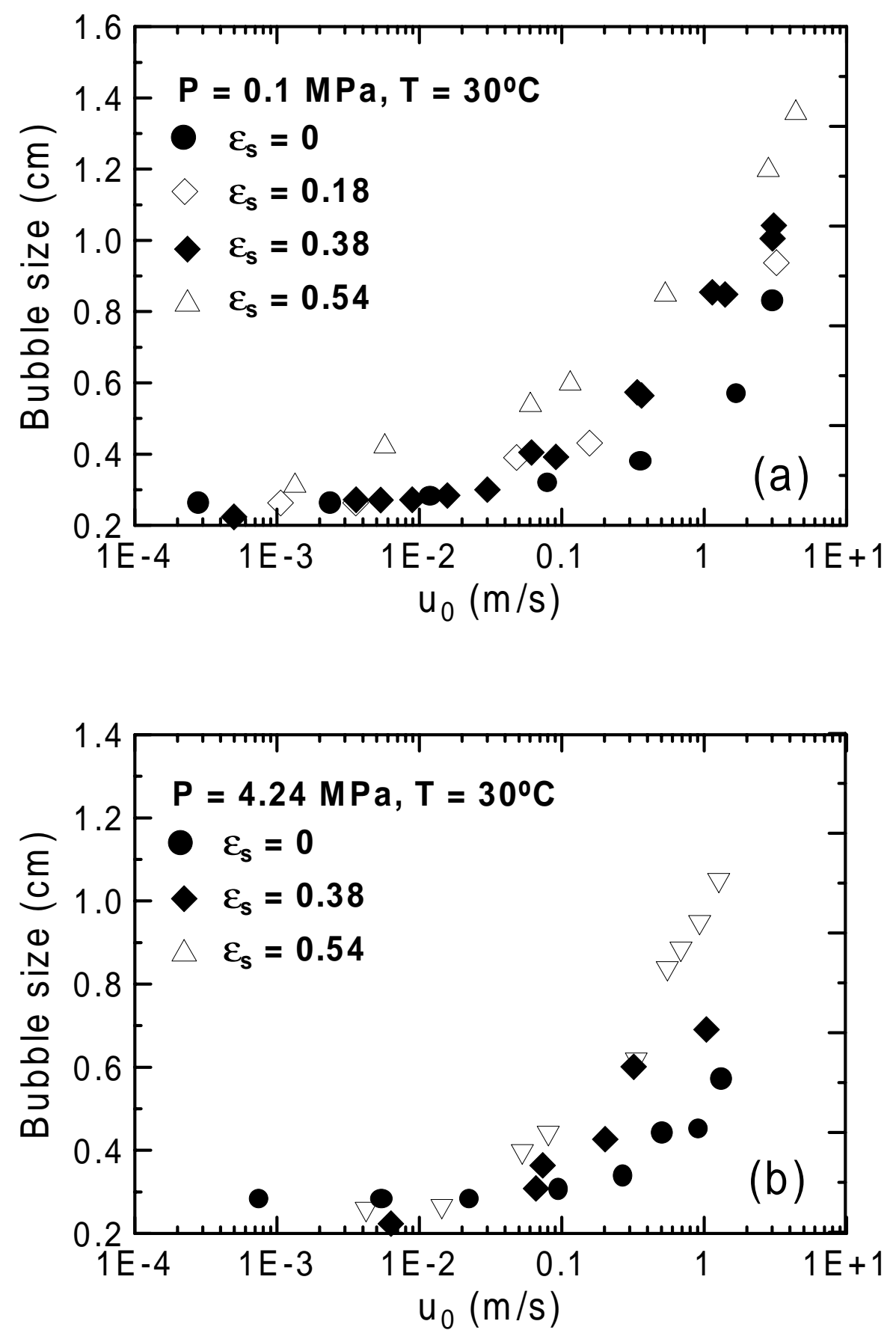

Figure 3. Effect of particles on the initial bubble size at various orifice gas velocities: (a) $P$ $=0.1 \mathrm{MPa}$; (b) $\mathrm{P}=4.24 \mathrm{MPa}$. 


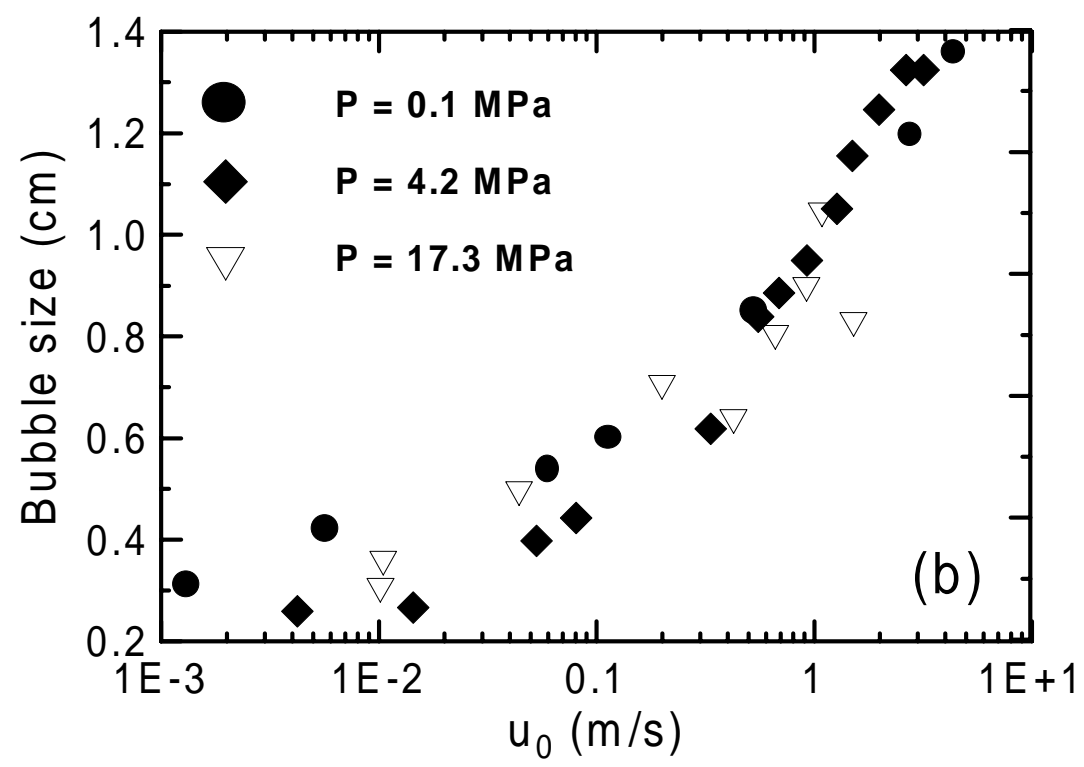

Figure 4. Effect of pressure on the initial bubble size in liquid and liquid-solid suspensions under constant flow conditions: (a) solids holdup $=0$; (b) solids holdup $=0.54$. 
Washington University in St. Louis

The report for Washington University for the period follows.

\title{
ENGINEERING DEVELOPMENT OF
}

SLURRY BUBBLE COLUMN REACTOR (SBCR) TECHNOLOGY

\author{
Thirteenth Quarterly Report \\ for \\ April 1 - June 30, 1998
}

(Budget Year 3: October 1, 1997 - September 30, 1998)

\author{
Submitted to
}

Air Products and Chemicals

Contract No.: DE-FC 2295 PC 95051

\section{Chemical Reaction Engineering Laboratory \\ Chemical Engineering Department \\ Washington University}




\section{Objectives for the Third Budget Year}

The main goal of this subcontract from the Department of Energy via Air Products to the Chemical Reaction Engineering Laboratory (CREL) at Washington University is to study the fluid dynamics of slurry bubble columns and address issues related to scaleup and design. The objectives for the third budget year (October 1, 1997 - September 30, 1998) were set as follows:

- Further development of phenomenological models for liquid and gas flow.

- Testing of the models against available data from the LaPorte AFDU.

- Evaluation of turbulent parameters in 18-inch-diameter columns, with and without internals, using collected CARPT data in these columns.

- Development of relationships between fundamental and simpler practical models for industrial use.

- Further improvement in fundamental computational fluid dynamics models and testing of the models against the CARPT/CT data.

- Preliminary assessment of differences in gas-liquid and gas-liquid-solid systems.

- Testing the effect of the gas distributor on flow patterns.

In this report, the research progress and achievements accomplished in the thirteenth quarter (April 1 - June 30, 1998) are discussed.

\section{Outline of Accomplishments}

\section{- Scaleup Procedure for Turbulent Eddy Diffusivity}

Correlations for the estimation of turbulent eddy diffusivities are developed based on the existing limited database for scaleup and design of bubble columns. The cross-sectional averaged axial and radial turbulent eddy diffusivities obtained by the Computer Automated Radioactive Particle Tracking (CARPT) in air-water in three column sizes (14, 19 and $44 \mathrm{~cm}$ diameters) are used to develop these correlations. Because of the limited number of data points available, the developed correlations represent a preliminary attempt to describe the effects of scale and superficial gas velocities on the turbulent diffusivities. The developed scaleup procedure for the gas holdup, liquid recirculating velocity (reported in the $12^{\text {th }}$ quarterly report) and eddy diffusivities enables the estimation of these parameters in systems of industrial interest. Accordingly, such a procedure allows us to utilize the developed fundamental two-dimensional convection-diffusion model to interpret the liquid tracer data obtained in the AFDU at LaPorte. 
- Interpretation of the Liquid Phase Tracer Data During Methanol Synthesis at the LaPorte AFDU using the Fundamental Two-Dimensional Convection-Diffusion Model

The fundamental two-dimensional convection-diffusion model has been developed to interpret the liquid phase tracer data taken at the LaPorte AFDU during methanol synthesis. Based on the developed scaleup methodology, model parameters were obtained from CARPT measurements using as input the estimated radial gas holdup profile at LaPorte. The gas holdup profile at LaPorte was estimated from the Nuclear Gauge Densitometry and pressure drop measurements. The results show that the model provides a good representation of the internal liquid mixing in bubble columns. The developed scaleup procedure for evaluating the model parameters in the AFDU slurry bubble column reactor during methanol synthesis results in fairly good predictions of the characteristic mixing times within the column, as measured by the radiation detectors at various axial locations.

During this quarter, the work has been completed on i) estimation of the liquid phase turbulent mixing length from CARPT and CT measurements for use in simulation with the CFDLIB code and ii) comparison of time-averaged liquid/slurry "turbulent" parameters in gas-liquid (G-L) and gas-liquid-solid (G-L-S) slurry bubble columns. However, the findings have not yet been organized in a report format. This will be accomplished during the next quarterly report. 


\section{TABLE OF CONTENTS}

\section{Section No.}

Objectives for the Third Budget Year

Outline of the Accomplishments

Table of Contents

\section{Scale-up Procedure for the Turbulent Eddy Diffusivity}

1.1 Turbulent Eddy Diffusivities

1.2 Characterization of Churn-Turbulent Bubble Columns

\subsection{Summary}

\subsection{References}

2. Interpretation of the liquid Phase Tracer data During Methanol Synthesis at AFDU, La Porte, Using the Fundamental Two-Dimensional Convection-Diffusion Model

2.1 Two-Dimensional Convection-Diffusion Model for Liquid Mixing in Bubble Columns

2.2 Numerical Procedure for Solution of Model Equations

2.3 Case I: Air-Water System

2.4 Case II: Interpretation of the AFDU Tracer Data

2.5 Summary

2.6 References 


\section{Scaleup Procedure for the Turbulent Eddy Diffusivity}

Studies of the effects of equipment scale and operating conditions on fluid dynamic parameters using experimental data obtained by Computer Automated Radioactive Particle Tracking (CARPT) and Computed Tomography (CT) and from the literature will aid in the design and scaleup of bubble column reactors. Our specific focus is on utilizing the available hydrodynamic information to model liquid mixing in bubble columns in the churn-turbulent flow regime. In this regard, the fluid dynamic parameters of interest are the gas holdup and radial holdup profile, the liquid recirculation velocity and liquid turbulence, which can be quantified by the turbulent eddy diffusivities.

Therefore, a scaleup methodology for gas holdup, liquid recirculating velocity and turbulent eddy diffusivity has been developed. The aim is to develop a basis for the approximate characterization of churn-turbulent bubble columns that enables the estimation of these fluid dynamic parameters in industrial-scale units based on measurements of these parameters in airwater atmospheric systems. This should enable the use of the developed two-dimensional convection-diffusion model to interpret liquid phase tracer data taken at the Alternative Fuels Development Unit (AFDU) at LaPorte, Texas during methanol synthesis.

In the last quarterly report (no. 12) the scaleup procedures developed for the gas holdup and liquid recirculating velocity were reported. Here, a scaleup procedure for the turbulent eddy diffusivities is outlined.

\subsection{Turbulent Eddy Diffusivities}

The cross sectionally averaged axial and radial turbulent eddy diffusivities are defined, respectively, as

$$
\begin{aligned}
& \bar{D}_{z z}=2 \int_{0}^{l} D_{z z}(\xi) \xi d \xi \\
& \bar{D}_{r r}=2 \int_{0}^{l} D_{r r}(\xi) \xi d \xi
\end{aligned}
$$

In this case, the current results from CARPT data in an air-water system and three column sizes, 14,19 , and $44 \mathrm{~cm}$, are considered. The data points shown in Figures 1.1 and 1.2 for $D_{z z}$ and $D_{\mathrm{rr}}$, respectively, are limited in their range of superficial gas velocity, $\mathrm{U}_{\mathrm{g}}$. Therefore, this represents only a preliminary attempt at scaling (extrapolating) $\mathrm{D}_{\mathrm{rr}}$ and $\mathrm{D}_{\mathrm{zz}}$, and needs to be substantiated with further experimental data at higher gas velocities, especially in the largest diameter $(44 \mathrm{~cm})$ column.

The following dependencies have been observed for $\bar{D}_{z z}$ and $\bar{D}_{r r}$ (based on CARPT data), and apply to large-diameter columns $(>10 \mathrm{~cm})$ in the churn-turbulent flow regime $\left(\mathrm{U}_{\mathrm{g}}>5\right)$. 


$$
\begin{aligned}
& \bar{D}_{z z}\left(\mathrm{~cm}^{2} / \mathrm{s}\right)=-\frac{2325}{D_{c}^{0.8}}+106.6 D_{c}^{0.3} U_{g}^{0.3} \\
& \bar{D}_{r r}\left(\mathrm{~cm}^{2} / \mathrm{s}\right)=-\frac{350}{D_{c}^{0.8}}+13.0 D_{c}^{0.3} U_{g}^{0.3}
\end{aligned}
$$

It is emphasized again that, due to the limited number of data points available, these equations represent only a preliminary assessment of the effects of scale and superficial gas velocity on turbulent diffusivities.

CARPT results for the average radial and axial eddy diffusivities in the churn-turbulent flow regime indicate that the radial profiles of the turbulent diffusivities can be approximately expressed as follows:

$$
D_{z z}(\xi)=\bar{D}_{z z} P_{4}
$$

where $P_{4}=-3.4979 \xi^{4}+3.2704 \xi^{3}+0.4693 \xi^{2}+0.005035 \xi+0.5847$

$$
D_{r r}(\xi)=\bar{D}_{r r} P_{2}
$$

where $P_{2}=-5.0929 \xi^{2}+5.0717 \xi+0.1653$

$\mathrm{P}_{4}$ and $\mathrm{P}_{2}$ are fourth-order and second-order polynomials that are independent of gas velocity and column diameter. This is illustrated in Figures 1.3 and 1.4, which show the profiles evaluated using Equations 1.5 and 1.6. The reasonably good comparisons suggest that Equations 1.5 and 1.6 in combination with Equations 1.3 and 1.4 can be used to estimate the profiles for the axial and radial eddy diffusivities as a function of column diameter, $\mathrm{D}_{\mathrm{c}}$, and superficial gas velocity, $\mathrm{U}_{\mathrm{g}}$, in air-water bubble columns operating in the churn-turbulent flow regime. 


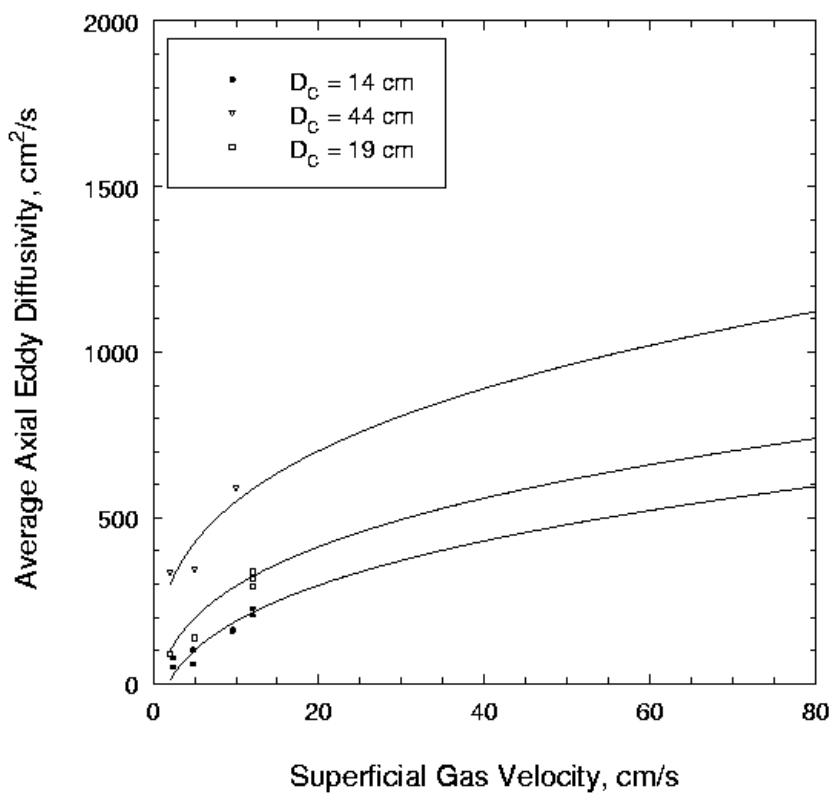

Figure 1.1 Effect of Superficial Gas Velocity and Column Diameter on the Average Axial Eddy Diffusivity

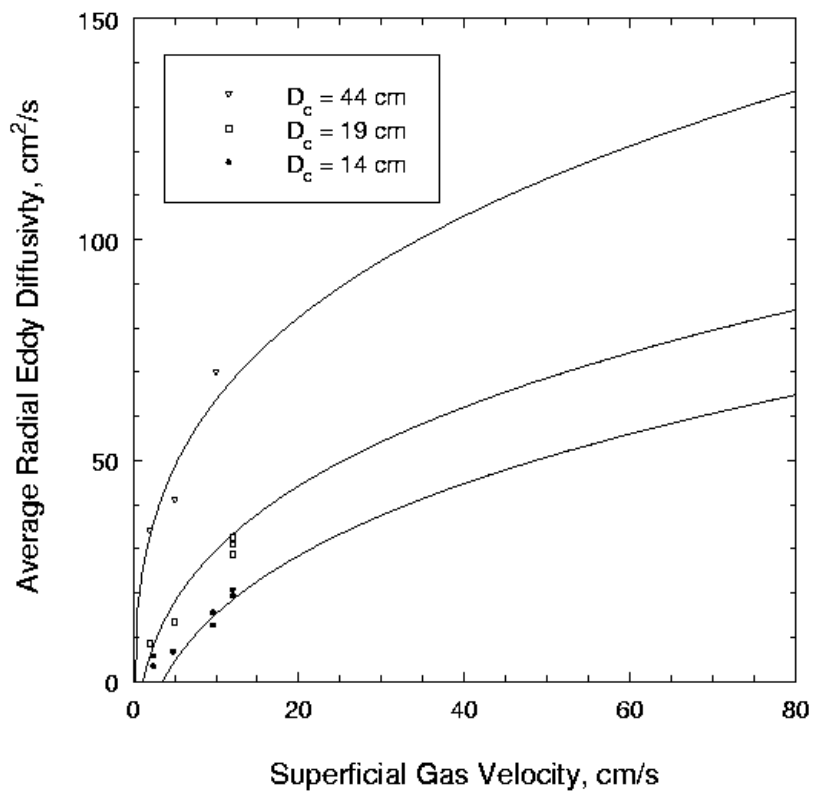

Figure 1.2 Effect of Superficial Gas Velocity and Column Diameter on Average Radial Eddy Diffusivity 


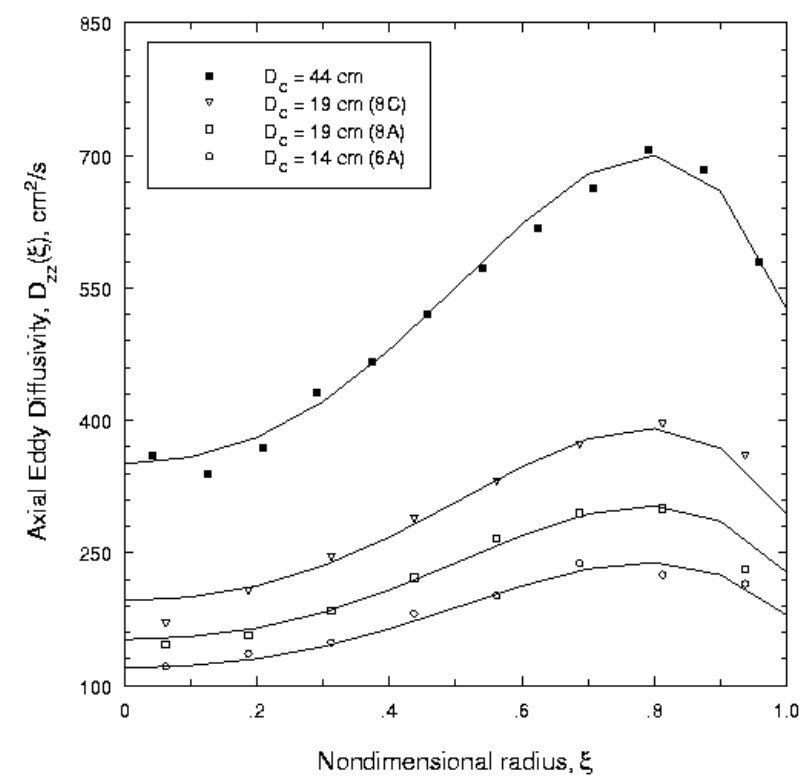

Figure 1.3 Radial Profile $\left(\mathrm{P}_{4}\right)$ of the Axial Eddy Diffusivity

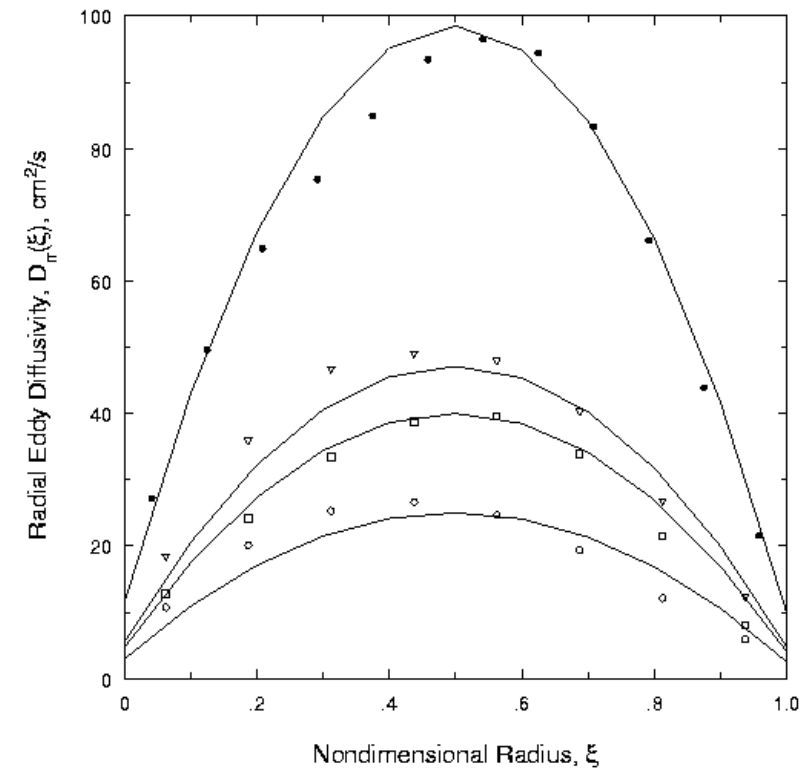

Figure 1.4 Radial Profile $\left(\mathbf{P}_{2}\right)$ of the Radial Eddy Diffusivity 


\subsection{Characterization of Churn-Turbulent Bubble Columns}

The scaleup equations for gas holdup and liquid recirculating velocity presented in the $12^{\text {th }}$ quarterly report and the equations for turbulent eddy diffusivities presented above have been developed for air-water atmospheric systems in the churn-turbulent regime. In this flow regime, the effects of the gas distributor and trace contaminants in water are expected be small. It is therefore assumed that at sufficiently high gas velocities for air-water systems, the fluid dynamic parameters are predominantly a function of superficial gas velocity and column diameter.

A change in system properties (e.g., physical properties of the fluids, presence of solids) and operating conditions (pressure and temperature) directly affects bubble sizes and their distribution, and thereby the global has holdup and holdup distribution in the column. This in turn influences the extent of liquid recirculation and turbulence characteristics in the system, which are essentially dictated by the passage and interaction of bubbles. For example, an increase in the system pressure tends to reduce the bubble size, which delays transition to turbulent flow regime, and therefore results in the increase in gas holdup, compared to values expected at atmospheric conditions. However, when the flow is in the churn-turbulent regime, it is typically characterized by the presence of large and small bubbles, irrespective of system pressure and other such factors (Krishna and Ellenberger, 1996; De Swart, 1996). Based on interpretation of dynamic gas disengagement (DGD) experiments, Krishna et al. (1994) conclude that the characteristics of the large bubbles are unaffected by system properties and pressure. Independent measurements of the local holdup profile in high-pressure bubble columns, at high gas velocities (Adkins et al., 1996), indicate that the holdup profile is parabolic $(\mathrm{m}=2$ in Equation 1.7), similar to the case for air-water systems at atmospheric pressure.

$$
\varepsilon_{g}=\widetilde{\varepsilon}_{g} \frac{m+2}{m}\left(1-c \xi^{m}\right)
$$

From these observations it is inferred that well into the churn-turbulent flow regime, similar bimodal bubble size distribution is present in the column, irrespective of system properties (except when viscosity is very high). It is essentially the resulting gas holdup and its radial distribution that dictate liquid recirculation and turbulence. Therefore, the unified characterization of churn-turbulent bubble columns can be employed to approximately evaluate $\bar{u}_{r e c}, \bar{D}_{z z}$ and $\bar{D}_{r r}$ in industrial systems of interest, based on the knowledge of these parameters in air-water systems, as shown in Figure 1.5. For a given process condition, with prior knowledge of the global gas holdup in the column, an equivalent superficial gas velocity, $U_{g e}$, which would exist at atmospheric conditions in such a column in an air-water system, can be evaluated using Equation 1.8.

$$
\bar{\varepsilon}_{g}=0.07 U_{g}^{0.474-0.000626 D_{c}} \quad \text { (in cgs units) }
$$

The calculated $U_{g e}$ can then be substituted in Equations 1.1 to 1.4, as well as Equation 1.9, to estimate the average turbulent diffusivities and average recirculation rate in the column under the specific conditions of interest. 


$$
\bar{u}_{r e c}(\mathrm{~cm} / \mathrm{s})=2.2 D_{c}^{0.4} U_{g}^{0.4}
$$

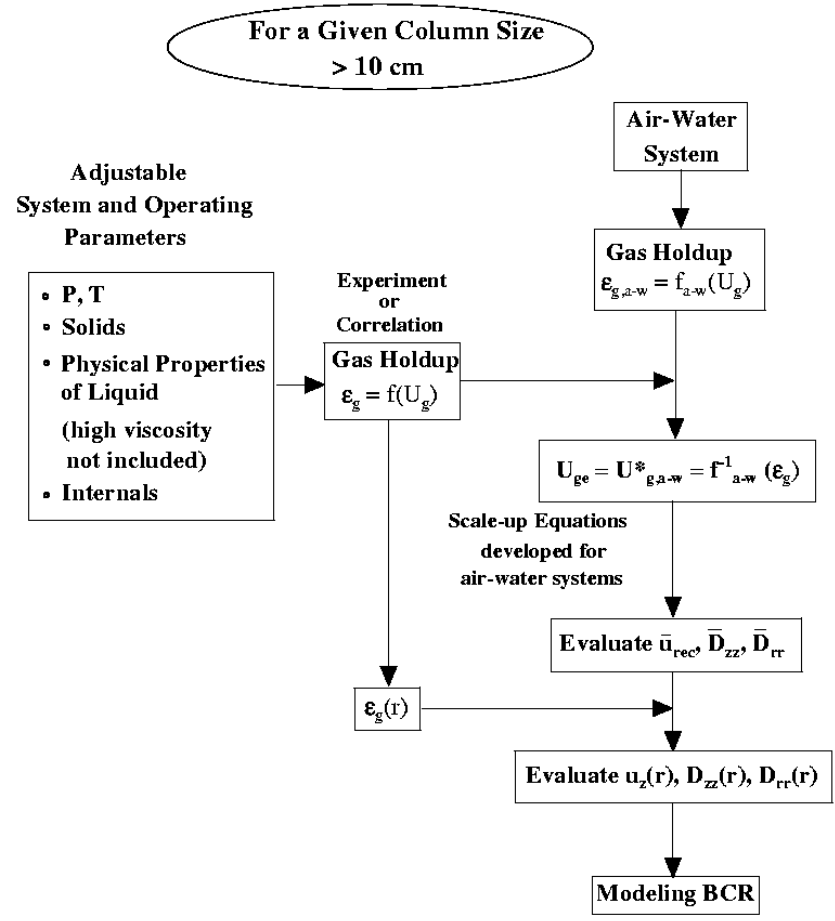

Figure 1.5 Method of Characterization of Churn-Turbulent Bubble Columns

The fluid dynamic parameters estimated from the above procedure are used in the phenomenological modeling of liquid mixing in an industrial slurry bubble column reactor, namely the AFDU in LaPorte, Texas.

\subsection{Summary}

Using experimental data obtained by CARPT/CT and from the literature, equations have been developed to predict the mean liquid recirculating velocity and average eddy diffusivities in airwater atmospheric systems. Based on the unified characterization of churn-turbulent bubble columns, a methodology has been proposed which enables the estimation of the mean liquid recirculating velocity and turbulent eddy diffusivities, in churn-turbulent flow regime, in systems of industrial interest (e.g., high pressure and high temperature), using the data generated in airwater systems. This strategy requires a knowledge of the global holdup and holdup distribution in the system under consideration.

The equations and proposed methodology for the scaleup of churn-turbulent bubble columns require substantiation with additional experimental data for the fluid dynamic parameters in large columns, at higher gas velocities and in different systems. Once verified, these will serve as tools by which data from a limited database can be utilized to model and scale up bubble columns, under process conditions, in the churn-turbulent flow regime. The following section 
discusses an indirect verification of the scaleup strategy, which was accomplished by interpreting the experimental liquid tracer data obtained in the LaPorte ADFU.

\subsection{References}

Adkins, D. R., K. A. Shollenberger, T. J. O'Hern, and J. R. Torczynski, "Pressure Effects on Bubble Column Flow Characteristics," ANS Proceedings of the National Heat Transfer Conference, THD-Vol. 9, 318-325 (1996).

De Swart, J. W. A., "Scaleup of a Fischer-Tropsch Slurry Reactor,” Ph.D. Thesis, University of Amsterdam, The Netherlands (1996).

Degaleesan, S., "Fluid Dynamic Measurements and Modeling of Liquid Mixing in Bubble Columns," D.Sc. Thesis, Washington University, St. Louis, MO (1997).

Krishna, R., and J. Ellenberger, "Gas Holdup in Bubble Column Reactors Operating in the Churn-Turbulent Flow Regime," AIChE J., Vol. 42, 2627-2634 (1996).

Krishna, R., J. W. A. de Swart, D. E. Hennephof, J. Ellenberger, and H. C. J. Hoefsloot, "Influence of Increased Gas Density on Hydrodynamics of Bubble Column Reactors," AIChE J., Vol. 40, 112-119 (1994).

\section{Interpretation of the Liquid Phase Tracer Data during Methanol Synthesis at the LaPorte AFDU using the Fundamental Two-Dimensional Convection-Diffusion Model}

A two-dimensional convection-diffusion model for liquid mixing in bubble columns has been developed to interpret the liquid phase tracer data taken at the LaPorte AFDU during methanol synthesis. The model equations were reported in the seventh quarterly report. The model characterizes, in a statistical sense, the large-scale flow pattern and mixing in the column, which should prove useful for the design and scaleup of bubble column reactors.

It is noted that, since long time averaging is used to arrive at the model equations, the current model only describes the meso- and macro-scale mixing in the column. Micromixing phenomena are not captured, but this is not a serious drawback since most of the reactions in bubble columns are slow to moderately fast, and the characteristic reaction time is longer than the micromixing time scale.

In this section, the two-dimensional convection-diffusion model developed is used to interpret the liquid phase tracer runs performed during methanol synthesis at the LaPorte AFDU. The model parameters obtained were based on the developed scaleup methodology from CARPT measurements using as input the estimated radial gas holdup profile at LaPorte, which was estimated from the Nuclear Gauge Densitometry and pressure drop measurements. The developed scaleup procedure for the gas holdup and liquid recirculating velocity was reported in 
the previous quarterly report $\left(12^{\text {th }}\right.$ quarter), while the turbulent eddy diffusivities are provided in Section 1 of this report.

Although the developed model was described in the seventh quarterly report, we re-state it here for clarity and for ease in following its implementation.

\subsection{Two-Dimensional Convection-Diffusion Model for Liquid Mixing in Bubble Columns}

The fundamental two-fluid model mass balance equation for the local, instantaneous tracer species for phase $k$ is given by the following equation:

$$
\frac{\partial \rho_{k} C_{k}}{\partial t}+\nabla \cdot \rho_{k} C_{k} \vec{u}_{k}-D_{m} \nabla^{2} C_{k}=0
$$

with an interfacial jump condition for mass transfer across the interface:

$$
\sum_{k=1}^{2} \rho_{k} C_{k}\left[\vec{u}_{k}-\vec{u}_{k i}\right] \cdot \vec{n}_{k}=0
$$

In the equation above, the phase density, $\rho_{k}$, for incompressible flows such as those in bubble columns, can be considered to be constant. $D_{m}$ is the molecular diffusivity, which is small and will be ignored hereafter. Phasic or ensemble averaging of the above equation in an axisymmetric system for an inert, non-volatile tracer yields:

$$
\begin{aligned}
& \frac{\partial}{\partial t}\left(\rho_{k} \varepsilon_{k}\left\langle C_{k}\right\rangle^{x}\right)+\frac{\partial}{\partial z} \rho_{k}\left(\varepsilon_{k}\left\langle u_{z, k}\right\rangle^{x}\left\langle C_{k}\right\rangle^{x}+\varepsilon_{k}\left\langle u_{z, k}^{\prime} C_{k}^{\prime}\right\rangle^{x}\right)+ \\
& \frac{1}{r} \frac{\partial}{\partial r} r \rho_{k}\left(\varepsilon_{k}\left\langle u_{z, k}\right\rangle^{x}\left\langle C_{k}\right\rangle^{x}+\varepsilon_{k}\left\langle u_{z, k}^{\prime} C_{k}^{\prime}\right\rangle^{x}\right)=\left\langle\rho_{k} C_{k}\left(\vec{u}_{k}-\vec{u}_{k i}\right) . \nabla X_{k}\right\rangle
\end{aligned}
$$

where $<>^{x}$ represents phasic averaging. The right-hand side of Equation 2.3 represents the term due to mass transfer across the interface, where $X_{k}$ is the phase function and is defined as in Equation 2.4.

$$
X_{k}(\vec{x}, t)=\left\{\begin{array}{lr}
1 & \text { if } \vec{x} \text { is in phase } k \text { at timet } \\
0 & \text { otherwise }
\end{array}\right.
$$

An additional source term to represent reaction can be added to the right-hand side of the equation. For the current situation, considering a non-volatile inert liquid tracer, the right-hand side of Equation 2.3 is set to 0 . Since the model is primarily concerned with the liquid phase, the subscript $k=l$, denoting the liquid phase, is dropped. In addition, all symbols denoting averaging are dropped in order to simplify notation. All the variables representing the fluid dynamic parameters and the tracer concentration will denote the phase-averaged quantities.

The cross-correlation terms between the fluctuating velocity and tracer concentration are closed using a standard gradient diffusion model (Hinze, 1975; Tennekes and Lumley, 1971; Seinfeld, 1986), as 


$$
\left\langle u_{z}^{\prime} C^{\prime}\right\rangle^{x}=-D_{z r} \frac{\partial C}{\partial r}-D_{z z} \frac{\partial C}{\partial z}
$$

and

$$
\left\langle u_{r}^{\prime} C^{\prime}\right\rangle^{x}=-D_{r r} \frac{\partial C}{\partial r}-D_{r z} \frac{\partial C}{\partial z}
$$

but, CARPT experiments show that

$$
D_{z r}=D_{r z} \sim 0
$$

Therefore

$$
\begin{aligned}
& \left\langle u_{z}^{\prime} C^{\prime}\right\rangle^{x}=-D_{z z} \frac{\partial C}{\partial z} \\
& \left\langle u_{r}^{\prime} C^{\prime}\right\rangle^{x}=-D_{r r} \frac{\partial C}{\partial r}
\end{aligned}
$$

where $D_{z z}$ and $D_{r r}$ are the CARPT measured axial and radial turbulent eddy diffusivities, respectively. Therefore, the final form of the model equation is:

$$
\frac{\partial(\varepsilon C)}{\partial t}+\frac{\partial}{\partial z}\left(\varepsilon u_{z} C\right)+\frac{1}{r} \frac{\partial}{\partial r}\left(r \varepsilon u_{r} C\right)=\frac{1}{r} \frac{\partial}{\partial r}\left[r \varepsilon D_{r r} \frac{\partial C}{\partial r}\right]+\frac{\partial}{\partial z}\left[\varepsilon D_{z z} \frac{\partial C}{\partial z}\right]
$$

Standard boundary conditions are used with zero flux at the wall and at the centerline of the column. For the case with continuous flow of liquid through the column, a zero gradient is assumed at the outlet, with injection of tracer at the inlet. Equation 2.10 represents the averaged balance equation for the non-volatile liquid species, and is a transient, two-dimensional convection-diffusion equation. The phasic (or time) averaging refers to any time interval, which may be small or large.

Multiphase flows in bubble columns are highly transient in nature. Hence the length of the time interval considered in the averaging will affect the type of results obtained. Short time averages involve averaging conducted over a short time interval, long enough to smooth the variations across the interface, but short enough to capture some of the transient structures in the flow. These transient structures will vary in nature with the time interval of averaging. On the other hand, long time averaging results in a statistically stationary flow field, which is steady in time, in terms of all the fluid dynamic variables.

Two factors are of concern here in deciding the type of averaging to be considered for the above model equation. First, since the flow phenomena in bubble columns are highly turbulent and random in nature, a quantitative comparison of the fluid dynamic parameters, between model predictions and experimental measurements, can be made only with respect to the statistical properties of the flow field. This immediately implies that time or ensemble averaging is required. Second, since the current model is considered in a two-dimensional axisymmetric domain, the type of boundary conditions used (zero gradient at the centerline) will not permit the computation of physically realistic results describing the transient structures. A true transient 
behavior can only be represented in a fully three-dimensional flow model, which can capture the inherent vortical and spiraling motion of the flow in bubble columns.

For these reasons, we propose to consider long time averaging for the above model equation. The various averaged quantities in the above equation will hence refer to long time-averaged quantities and corresponding closure models (Equations 2.8 and 2.9). CARPT data for the long time-averaged liquid velocities, $u_{r}$ and $u_{z}$, and turbulent diffusivities, $D_{r r}$ and $D_{z z}$, along with CT data for the time-averaged liquid holdup profile, are used as input parameters to the model.

\subsection{Numerical Procedure for Solution of Model Equations}

A finite volume (also referred to as the control volume) method has been used to solve the convection-diffusion model (Patankar, 1983). In this scheme, the calculation domain is divided into a number of non-overlapping control volumes, such that there is a control volume surrounding each grid point. The governing equations are integrated over each volume, with piece-wise profiles for the variation in the dependent variables. This results in the discretization equation containing the values of the dependent variables for a group of grid points. The discretization equation obtained as such allows the conservation principle for a given quantity to be expressed for the finite control volume. The most attractive aspect of this method is that the resulting solution guarantees that the integral conservation of a given quantity is exactly satisfied over a single or group of control volumes, and therefore over the whole domain. Thus, even the coarse-grid solution exhibits exact integral balances.

\subsubsection{Discretization Considerations}

An implicit scheme is used in time, with upwinding for the convection term. Although the upwind scheme is only first-order accurate, it has been shown to have advantages in solving nonlinear systems with steep velocity gradients (Patankar, 1980), as in the case of bubble column flows. However, if the physical diffusion process is dominant (i.e., if $D_{z z}$ and $D_{r r}$ are very large), upwind differencing loses its advantages and requires finer discretization. A staggered grid configuration is used by assigning the scalar variables, namely the concentration and holdup to the cell center and the vector velocity variables and diffusivities to the cell faces (Figure 2.1). Advantages of using the staggered grid configuration, for solution of the momentum balance equations, have been discussed elaborately by Verstaag et al. (1995) and Patankar (1983). For solution of the convection-diffusion equation it poses no special advantage. 


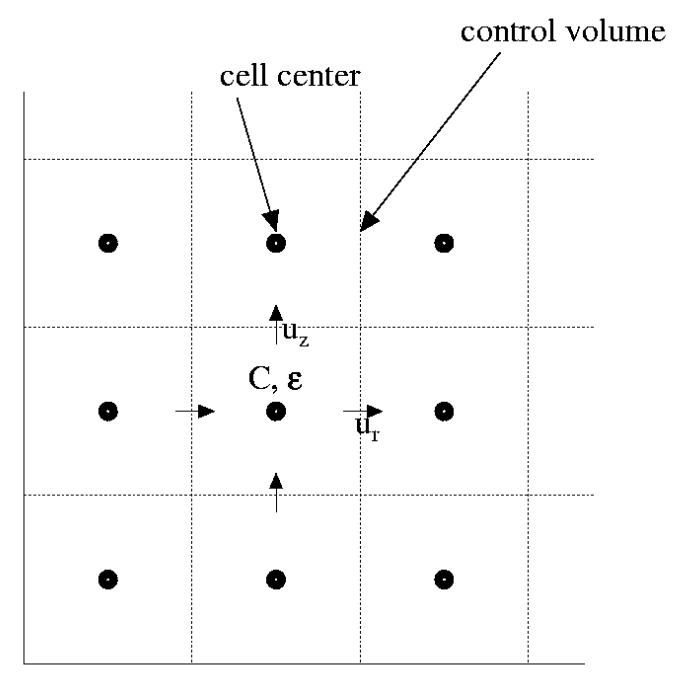

Figure 2.1 Variable Locations in a Staggered Grid

The above process of discretization results in a set of linear algebraic equations. Since the model equation is a transient convection-diffusion equation, this results in a sparse matrix. Therefore a direct method is used to solve the system of equations, based on LU decomposition. The model is two dimensional, resulting in extremely large number of equations that depend on the size of the domain studied. The SMPAK ${ }^{T M}$ solver, which uses an effective storage scheme to hold large sparse matrices, is used to solve the equations. This significantly reduces the memory and time (five times less than a standard solver) for computation. The spacing used in the three coordinates, $\Delta \mathrm{t}, \Delta \mathrm{z}$ and $\Delta \mathrm{r}$, are the numerical parameters that need to be considered. Although stability is not a concern since an implicit scheme is used, the issue of accuracy should be examined. For this purpose, several trials are made with increasingly fine discretizations, until an accurate solution is obtained.

There is considerable experimental evidence in the literature, including results from CARPT, which show that in columns of high aspect ratios, the time-averaged flow pattern is axisymmetric, with global liquid recirculation in the column. In a time-averaged sense, a largescale liquid circulation exists in the form of a recirculation cell, which occupies most of the column with respect to height, with liquid ascending along the central core region and descending along the annular region between the core and the walls. A single one-dimensional velocity profile is always identified in this recirculation cell, which is in the middle part of the column. Axial variations are evident in the distributor and free surface region, where the liquid turns around. In the middle region, there is evidence that all the other fluid dynamic parameters, such as the turbulent eddy diffusivities and the turbulent stresses, are also a function of radial position only.

The computation domain is therefore divided axially into three regions: a distributor zone at the bottom, a fully developed region where the radial liquid velocities are negligible and are considered to be zero, and finally the disengagement zone at the top where liquid turns around. The distributor and disengagement zones are assumed to extend over a height equal to one 
column diameter, based on experimental considerations. However, varying the height from 1 to 2 times the column diameter does not affect the results significantly (Figure 2.6), especially for column aspect ratios greater than 10. In the distributor zone and the disengagement zone, the domain is discretized only in the radial direction, as shown in Figure 2.2. In both these regions where the radial liquid velocities are significant, the solution of the equations becomes very sensitive to the radial velocities. The velocities assigned to these regions are therefore fitted to a smooth profile in order to satisfy liquid continuity for each control volume or cell, and therefore the entire domain. In the fully developed middle region, the domain is discretized both radially and axially (Figure 2.2), and the radial liquid velocities are set to zero.

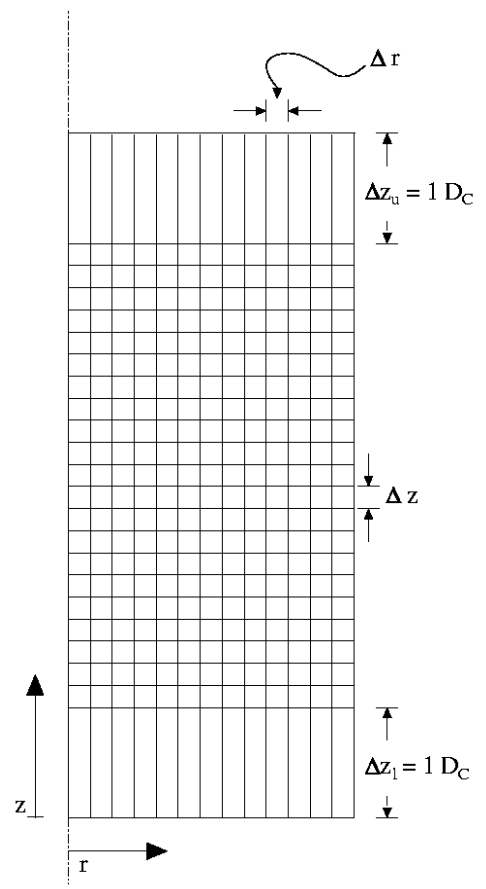

Figure 2.2 Schematic of Column Discretization

The other fluid dynamic variables, i.e., the axial liquid velocity, axial and radial turbulent eddy diffusivities, are considered to be a function of radial position only, and independent of axial location in the middle section of the column. Experimental data from CT for the gas holdup is first fitted to the power law expression given by Equation 2.11 to obtain the radial liquid holdup profile. This profile is then used as an input to the one-dimensional liquid recirculation model to obtain an axial liquid velocity profile that fits the experimental data from CARPT measurements under the same operating conditions.

$$
\varepsilon_{g}=\widetilde{\varepsilon}_{g} \frac{m+2}{m}\left(1-c \xi^{m}\right) \quad, \varepsilon_{l}=1-\varepsilon_{g}
$$

These radial profiles for the liquid holdup and velocity are used as input to the model in the middle, fully developed section of the column, along with radial profiles for the axial and radial turbulent eddy diffusivities. Using these calculated profiles for the holdup and velocity ensures 
that continuity is satisfied in the entire domain. The developed model, as represented by Equation 2.10, is used to simulate tracer responses for different cases for which experimental data are available.

\subsection{Case I: Air-Water System}

The model is first tested in a column under operating conditions for which experimental data for the fluid dynamic parameters are directly available. The case considered is the tracer data of Myers et al. (1986), whose experiments were conducted in an air-water system in a $19-\mathrm{cm}$ diameter column, at a superficial gas velocity of $10 \mathrm{~cm} / \mathrm{s}$ and liquid velocity of $1 \mathrm{~cm} / \mathrm{s}$. The mode of operation, in this case, is therefore a cocurrent bubble column with a continuous flow of liquid and gas. The following boundary conditions are used:

$$
\begin{gathered}
r=0, \text { and } r=R ; \quad \frac{\partial C}{\partial r}=0 \\
z=0, C(r, 0, t)=\delta(t) ; \quad z=L, \quad \frac{\partial C}{\partial z}=0 \\
t=0, C(r, z, 0)=0
\end{gathered}
$$

A time step of $0.5 \mathrm{sec}$ along with a radial grid size of $0.38 \mathrm{~cm}$ and an axial grid size of $1 \mathrm{~cm}$ were found to be optimum discretizations. In the end zones, the cell heights were assigned to be equal to the column diameter. In order to solve the model for the present case, CARPT and CT experiments were performed under identical conditions to obtain the input hydrodynamic parameters for the system. Results are shown in Figures 2.3, 2.4 and 2.5 for the onedimensional, time-averaged axial liquid velocity, liquid holdup profile and turbulent eddy diffusivities, respectively. 


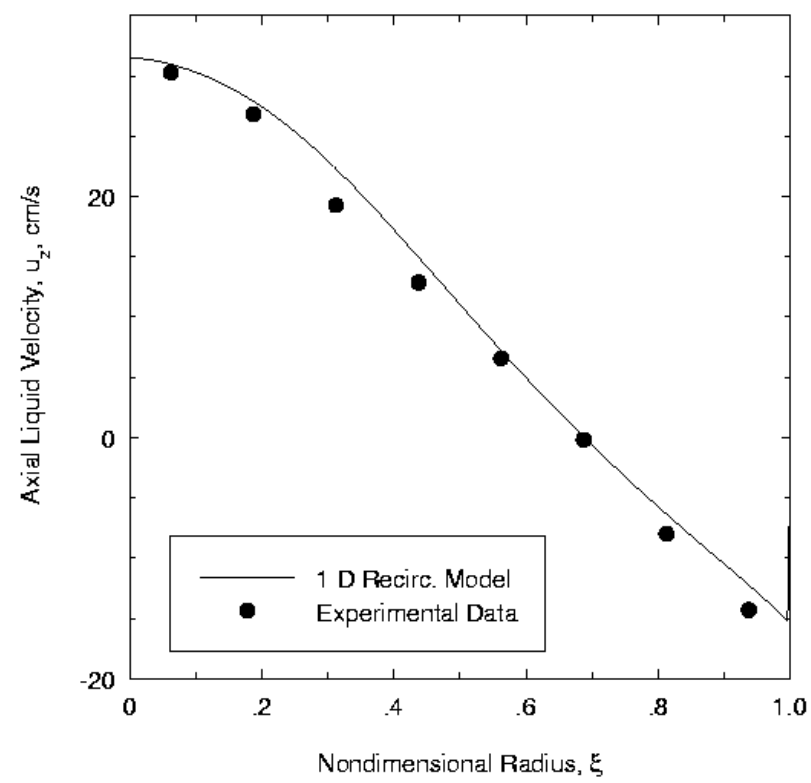

Figure 2.3 Time-Averaged, One-Dimensional Axial Liquid Velocity Profile: Column Diameter $19 \mathrm{~cm}, \mathrm{U}_{\mathrm{g}}=10 \mathrm{~cm} / \mathrm{s}$

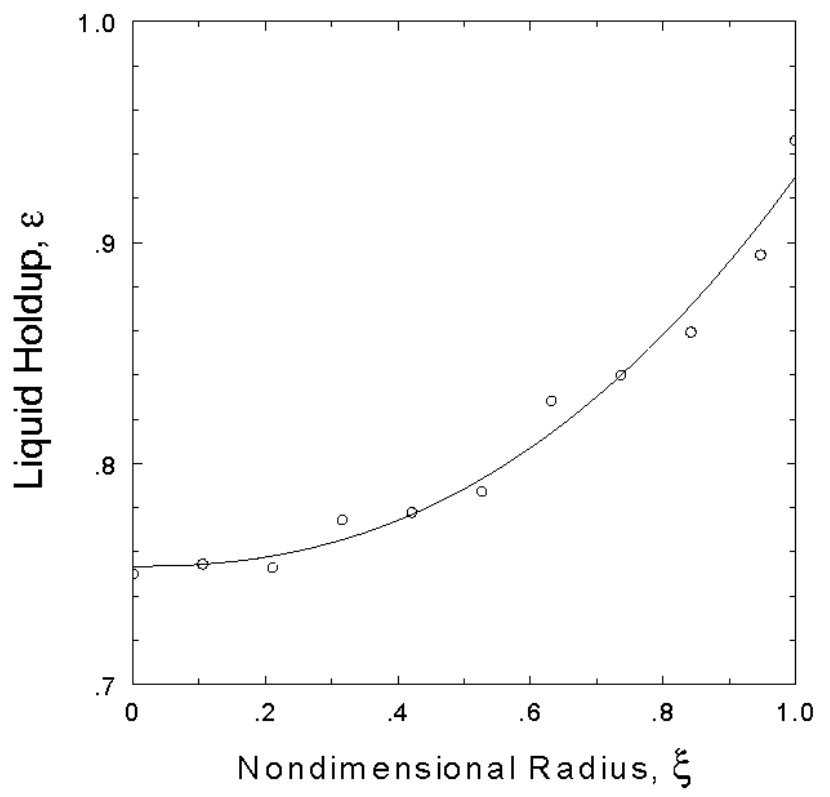

Figure 2.4 Time Averaged Liquid Holdup Profile: Column Diameter $19 \mathrm{~cm}, \mathrm{U}_{\mathrm{g}}=10 \mathrm{~cm} / \mathrm{s}$

In Figure 2.3, the solid circles represent the axial liquid velocity axially averaged in the middle section of the column. The curve is the one-dimensional recirculation model prediction, using the input holdup profile from CT measurements (shown in Figure 2.4), along with a mixing length profile obtained from CARPT data. With these profiles for the liquid velocity and holdup, continuity is satisfied within $98 \%$. The experimental data for the turbulent diffusivities, in Figure 2.5, are directly used as input to the model. 


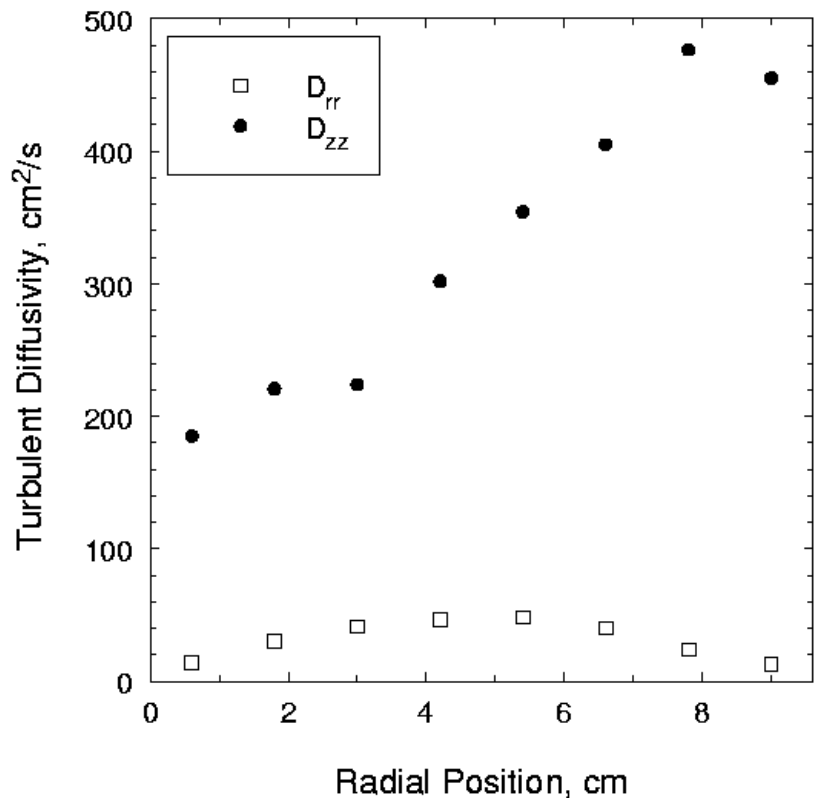

Figure 2.5 One Dimensional Turbulent Eddy Diffusivities: Column Diameter $19 \mathrm{~cm}, \mathrm{U}_{\mathrm{g}}=$ $10 \mathrm{~cm} / \mathrm{s}$

With the above parameters as input, the model (i.e., Equation 2.10) is solved to predict the overall tracer impulse response of the given system, shown in Figure 2.6. Here, $\mathrm{E}(\mathrm{t})$ is evaluated as follows:

i. The model (via equation 2.10) calculates $\mathrm{C}(\mathrm{r}, \mathrm{z}=\mathrm{L}, \mathrm{t})$.

ii. The mixing cup concentration is calculated by Equation $2.14 \mathrm{a}$.

iii. $\mathrm{E}(\mathrm{t})$ is then calculated by Equation $2.14 \mathrm{~b}$.

$$
\begin{aligned}
& \bar{C}(z=L, t)=\frac{\int_{0}^{R} r \varepsilon u_{z} C(r, z=L, t) d r}{\int_{0}^{R} r \varepsilon u_{z} d r} \\
& E(t)=\frac{\overline{\mathrm{C}}(\mathrm{z}=\mathrm{L}, \mathrm{t})}{\int_{0}^{\infty} \bar{C} d t}
\end{aligned}
$$

The comparison between the two-dimensional model prediction of the normalized exit mixing cup concentration and the experimental tracer response curve from Myers et al. (1986) (Figure 2.6) suggests that the model provides a good representation of the experimental data. Therefore, a fundamentally based model, with experimental data for the fluid dynamic parameters, is able to capture the overall mixing in the system as described by the tracer residence time distribution (RTD). 


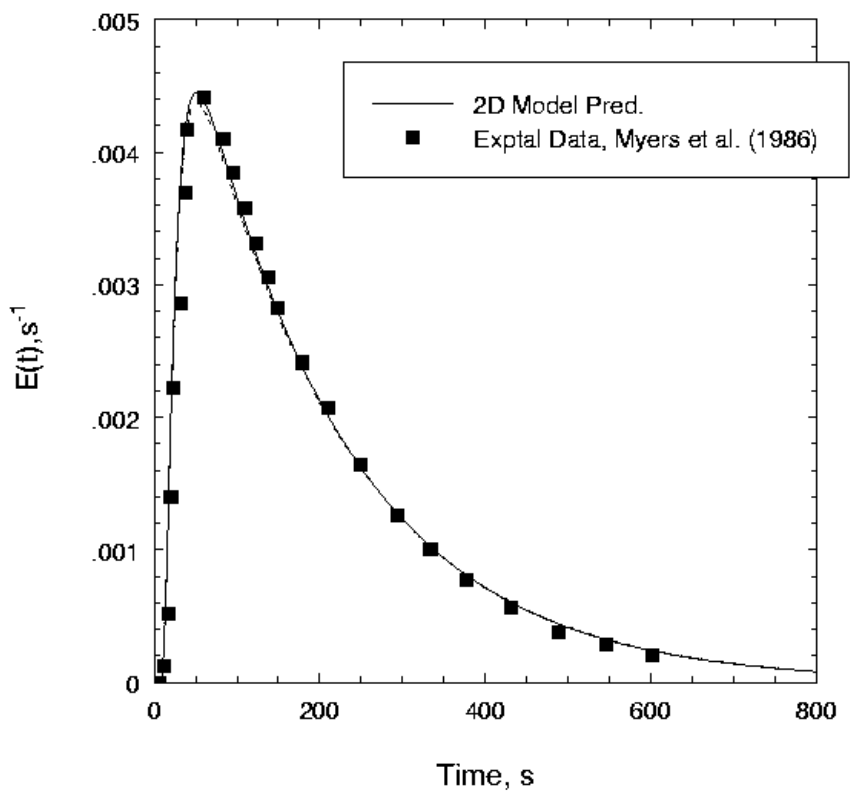

Figure 2.6: Comparison of Experimental Tracer Response with 2D Model Prediction (dashed line is for cell heights in end zones, equal to two column diameters while solid line is for heights of end zones equal to one column diameter).

\subsection{Case II: Interpretation of the AFDU Tracer Data}

\subsubsection{Experimental Details}

The radioactive tracer experiments were conducted by Air Products and Chemicals, Inc. in DOE's LaPorte, Texas Alternate Fuels Development Unit (AFDU), which is a slurry bubble column reactor, to study the backmixing characteristics of the gas and liquid phase in this reactor during methanol synthesis. Powdered methanol catalyst ( $\sim 5 \mathrm{wt} \%$ loading) suspended in an inert hydrocarbon oil forms the batch slurry phase. Synthesis gas is bubbled through a sparger placed at the bottom of the reactor. The gas disengages from the oil in the freeboard section of the reactor, and the unreacted feed gas is recycled back to the reactor.

The principal reaction for methanol synthesis is

$$
\mathrm{CO}+2 \mathrm{H}_{2} \Leftrightarrow \mathrm{CH}_{3} \mathrm{OH}
$$

At the process conditions used, the methanol formed is in the vapor phase. The feed gas to the reactor is synthesis gas, which is a mixture typically consisting of $\mathrm{CO}(30 \%), \mathrm{H}_{2}(60 \%), \mathrm{CO}_{2}$ $(5 \%)$ and inerts $\left(\mathrm{N}_{2}\right)$. The composition of the feed gas may be varied by changing the feed ratio, depending upon process requirements. The presence of $\mathrm{CO}_{2}$ is usually required, as it serves to initiate the reaction. A side reaction known to occur is the water gas shift reaction:

$$
\mathrm{H}_{2}+\mathrm{CO}_{2} \Leftrightarrow \mathrm{H}_{2} \mathrm{O}+\mathrm{CO}
$$


Based on the above reaction stoichiometry (Equations 2.15 and 2.16), there is a reduction in the volume of the gas due to reaction. The actual reduction depends on the feed rate, composition, and conversion. For the tracer runs studied, feeds with varying composition were used. The experimental conditions along with the feed compositions, observed conversions and changes in gas volumetric flow rate are reported in Table 2.1. The conversion of $C O$ for the three runs studied ranges from $16 \%$ to $33 \%$. An excess of $C O$ results in lower conversion (Runs 14.6 and 14.7 compared to Run 14.8). Although $C O$ conversion varies for the three cases, due to a corresponding change in feed composition, the effective overall change in the gas flow rate is about the same for all runs, around $-18 \%$.

Table 2.1 Experimental Conditions (Temp : $250^{\circ} \mathrm{C}$ )

\begin{tabular}{|c|c|c|c|c|c|c|c|c|c|}
\hline \multirow[t]{2}{*}{$\begin{array}{l}\text { Run } \\
\text { No. }\end{array}$} & \multirow[t]{2}{*}{$\begin{array}{c}\mathrm{P} \\
\mathrm{MPa}\end{array}$} & \multirow{2}{*}{$\begin{array}{c}\text { Avg. } \\
\text { Gas } \\
\text { Holdup }\end{array}$} & \multirow{2}{*}{$\begin{array}{c}\text { Inlet } \\
U_{g 0} \\
\mathrm{~cm} / \mathrm{s} \\
\end{array}$} & \multicolumn{3}{|c|}{$\begin{array}{c}\text { Feed Compn. } \\
\text { Mol \% }\end{array}$} & \multirow{2}{*}{$\begin{array}{c}\text { Conv of } \\
\mathrm{CO} \text { to } \\
\mathrm{MeOH}\end{array}$} & \multirow{2}{*}{$\begin{array}{c}\text { Inlet Vol. } \\
\text { Flow Rate } \\
\text { SCFH } \\
\end{array}$} & \multirow{2}{*}{$\begin{array}{c}\text { Change in } \\
\text { Flow Rate } \\
\%\end{array}$} \\
\hline & & & & $\mathrm{H}_{2}$ & $\mathrm{CO}$ & $\mathrm{CO}_{2}$ & & & \\
\hline 14.6 & 5.2 & 0.39 & 25 & 35.4 & 50.8 & 12.7 & 15.9 & 143121 & -17.1 \\
\hline 14.7 & 5.2 & 0.33 & 14 & 35.0 & 50.9 & 12.7 & 17.5 & 81151 & -19.2 \\
\hline 14.8 & 3.6 & 0.38 & 36 & 60.2 & 24.0 & 10.3 & 33.0 & 141690 & -17.7 \\
\hline
\end{tabular}

\subsubsection{Gas Holdup Measurements}

Holdup measurements within the reactor were made using two techniques: 1 . Differential Pressure (DP) measurements and 2. Nuclear Density Gauge (NDG) measurements. From the experiments conducted, there is no definite trend for the axial gas holdup at different velocities. In addition, discrepancies exist between the two techniques.

DP measurements rely on the assumption that liquid (slurry) velocities and shear stresses near the wall are small in comparison with the hydrostatic head. Thereby

$$
\rho g=\frac{\Delta P}{\Delta z}
$$

where

$$
\rho=\rho_{l} \varepsilon_{l}+\rho_{g} \varepsilon_{g}
$$

The subscripts ' $\mathrm{l}$ ' and ' $\mathrm{g}$ ' refer to the slurry and gas phase, respectively. Based on experimental evidence, the slurry density in the column is assumed to be uniform $\left(\rho_{l}\right)$ and is calculated using the information on solids holdup ( (catalyst weight/density) / dispersion volume ) (Shollenberger 1995b). Therefore, from here on, the terms 'liquid' and 'slurry' are used interchangeably. The density of the gas phase is very small when compared with that of the slurry, and hence the second term in Equation 2.18 is usually ignored. Equation 2.18 in conjunction with Equation 2.17 can be used to calculate the average holdup between the two measurement sections (Figure 2.7). Assuming that there is no axial variation of holdup between the measurement sections, the volume average holdup calculated from DP measurements yields a cross-sectional mean holdup, $\bar{\varepsilon}_{g}$ : 


$$
\bar{\varepsilon}_{g}=2 \int_{0}^{1} \xi \varepsilon_{g}(\xi) d \xi
$$

Nuclear Densitometry (NDG) is a noninvasive method in which a narrow beam of radiation ( $\gamma$ ray) emitted through the center of the column, with the source on one side (Figure 2.7), is detected using a detector on the opposite side. Such a single chordal measurement obtained across the centerline (i.e., diameter) of the column results in a chordal average, $\hat{\varepsilon}_{g}$, defined by

$$
\hat{\varepsilon}_{g}=\int_{0}^{1} \varepsilon_{g}(\xi) d \xi
$$

which is not necessarily representative of the cross-sectional mean.

$\begin{array}{cc}\text { Nuclear Density Gauge } & \text { Differential Pressure } \\ \text { (NDG) } & \text { Measurement (DP) }\end{array}$
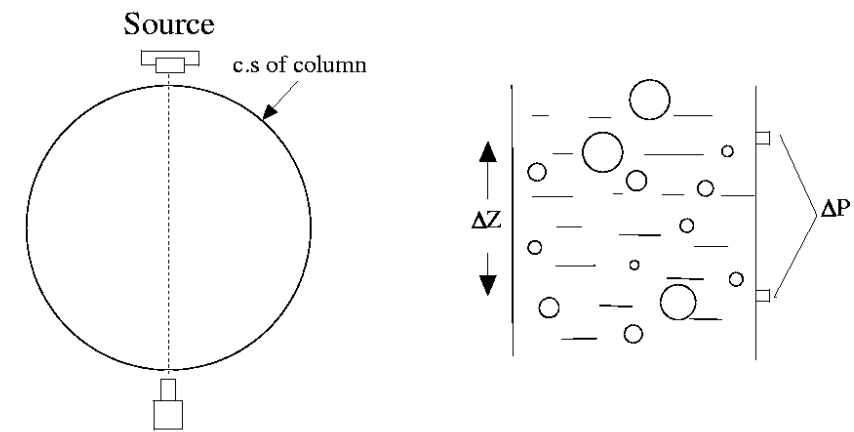

Detector

$$
\bar{\varepsilon}_{\mathrm{g}_{\mathrm{NDO}}}=\hat{\varepsilon}_{\mathrm{g}}=\frac{1}{2} \int_{-1}^{1} \varepsilon_{\mathrm{g}}(\xi) \mathrm{d} \xi \quad \bar{\varepsilon}_{\mathrm{g}_{\mathrm{DP}}}=\bar{\varepsilon}_{\mathrm{g}}=2 \int_{0}^{1} \varepsilon_{\mathrm{g}}(\xi) \xi \mathrm{d} \xi
$$

Figure 2.7 Schematic of DP and NDG Technique for the Measurement of the Average Gas Holdup

Therefore, there is a discrepancy between the average holdups measured by DP and NDG. Using Equation 2.11 for the radial gas holdup profile, the two averages $\bar{\varepsilon}_{g}$ and $\hat{\varepsilon}_{g}$ are found to be related by the following expression:

$$
\frac{\hat{\varepsilon}_{g}}{\bar{\varepsilon}_{g}}=\frac{(m+2)(m+1-c)}{(m+1)(m-2 c+2)}
$$

Since experimental measurements of $\hat{\varepsilon}_{g}$ and $\bar{\varepsilon}_{g}$ are available from NDG and DP, the axial average of these values is used to extract the void fraction exponents $m$ and $c$ in Equation 2.11, given above, which then provide the description of the radial void fraction profile existing in the 
column. Using the average gas holdup, $\bar{\varepsilon}_{g}$, in the entire reactor as measured by DP, the resulting void fraction profiles, calculated for all three process conditions, are shown in Figure 2.8.

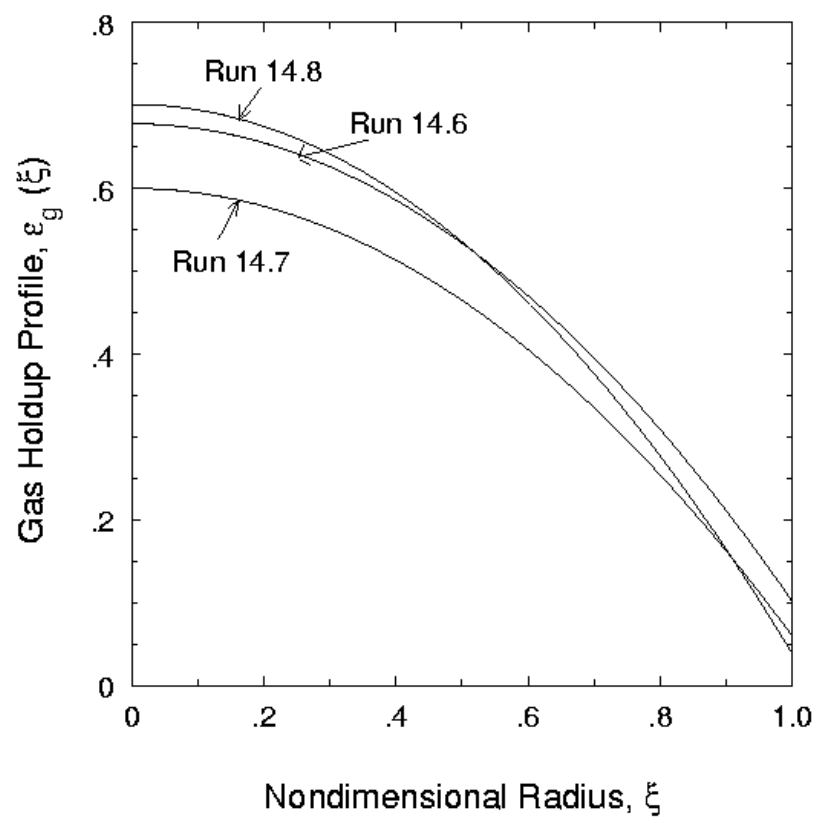

Figure 2.8 Radial Gas Holdup Profiles Calculated from Global Gas Holdup Measurements (DP and NDG) in the AFDU During Methanol Synthesis

\subsubsection{Tracer Experiments}

A schematic of the AFDU slurry bubble column reactor is shown in Figure 2.9. It has an internal diameter of $0.46 \mathrm{~m}$ and a height of $15.24 \mathrm{~m}$, with the liquid - gas - solid dispersion level maintained at $13.25 \mathrm{~m}$ (L/D ratio of 28.8) during the runs discussed here. The vapor phase and liquid phase tracer experiments were conducted separately. Radioactive Ar-41, used to study the residence time distribution of the vapor phase, was injected as a pulse at the inlet of the reactor. Radioactive Manganese-56 $(50 \mu \mathrm{m})$ particles mixed in oil were used for liquid (slurry) phase tracing. Four pulse injections were made at a given process rate: (1) lower nozzle N2 - 4.5 in. $(11.4 \mathrm{~cm})$ from wall, (2) nozzle N2 - at wall, (3) upper nozzle N1 - $4.5 \mathrm{in} .(11.4 \mathrm{~cm})$ from wall, and (4) nozzle N1 - at wall. The axial levels of these injection points are shown in Figure 2.9. The injections made at $4.5 \mathrm{in} .(11.4 \mathrm{~cm})$ from the wall are referred to as "center injections," as they are made into the core part of the column, where the liquid is known to move upward by convection in the time-averaged sense.

Radiation measurements from the vapor and liquid tracers were made using thirty 2" by 2" NaI scintillation detectors positioned outside the column at various axial levels, as shown in Figure 2.9. Sets of four detectors were placed at 90-degree angles at seven axial locations. In addition, detectors were placed at the inlet and outlet of the reactor. During the liquid tracer study, the 
inlet detector was placed close to the liquid injection point to monitor the shape of the injected pulse.

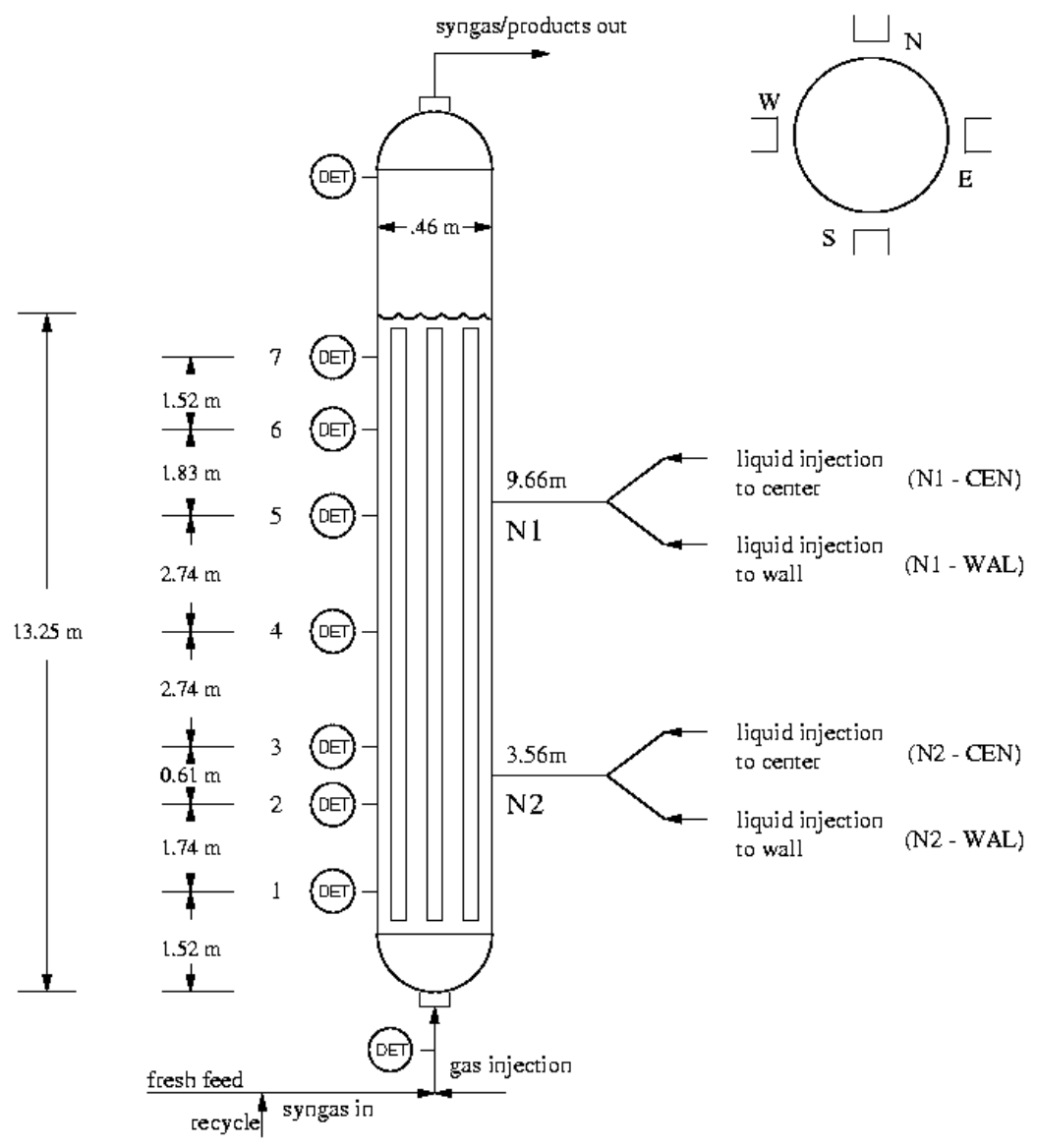

Figure 2.9 Schematic of Reactor for Tracer Experiments

The detectors were shielded on their sides, thereby allowing only the front circular surface of the detectors to be exposed to radiation. With this configuration, the spatial range from which a detector received most of its radiation was assessed. Details of these calculations are discussed in the fourth quarterly report for DOE (Degaleesan et al., 1996b). It has been shown that most of the intensity recorded at a detector, shielded on its sides, emanates from a slice of volume at the given axial level of the detector. For analyses purposes, only the tracer from the cross section of the reactor at the axial location of the detector is considered here.

\subsubsection{Model Parameters}

In order to use the current model to predict liquid tracer distribution in the column it is necessary to evaluate the model parameters. Experimental information exists only for the average gas holdup. From the holdup measurements using DP and NDG, there is an axial variation of the gas 
holdup in the reactor due to reaction. This variation is not very significant as far as the slurry phase mixing is concerned, and as a first approximation, the average gas holdup in the reactor as obtained from DP measurements is considered. The corresponding radial gas holdup profiles calculated using results from DP and NDG are shown in Figure 2.8. Information on the other fluid dynamic variables, namely, the liquid velocity profile and turbulent eddy diffusivities, does not exist. Hence, the preliminary scaleup rules and characterization methodology were used to evaluate the mean liquid recirculating velocity and average turbulent eddy diffusivities. Since the current experimental conditions involve high pressure and a slurry system, this significantly alters the overall gas holdup in the reactor (Wilkinson et al. 1992), which for the present case results in gas holdups higher than that at atmospheric conditions for air-water systems. Knowing the average gas holdup in the reactor (Table 2.1), and using Equation 2.22, the equivalent gas velocity, $U_{g e}$, for the three operating conditions is calculated (shown in Table 2.3).

$$
\bar{\varepsilon}_{g}=0.07 U_{g}^{0.474-0.000626 D_{c}} \quad \text { (in cgs units) }
$$

For Run 14.6, $U_{g e}=47 \mathrm{~cm} / \mathrm{s}$, which is considerably higher than the original inlet gas velocity of $25 \mathrm{~cm} / \mathrm{s}$. The estimated $U_{g e}$ is used in Equations 2.23 to 2.27, to evaluate the mean recirculation velocity and average axial and radial turbulent diffusivities under the existing conditions in the AFDU.

$$
\begin{aligned}
& \bar{u}_{r e c}(\mathrm{~cm} / \mathrm{s})=2.2 D_{c}^{0.4} U_{g}^{0.4} \\
& \bar{D}_{z z}=2 \int_{0}^{l} D_{z z}(\xi) \xi d \xi \\
& \bar{D}_{r r}=2 \int_{0}^{l} D_{r r}(\xi) \xi d \xi \\
& \bar{D}_{z z}\left(\mathrm{~cm}^{2} / \mathrm{s}\right)=-\frac{2325}{D_{c}^{0.8}}+106.6 D_{c}^{0.3} U_{g}^{0.3} \\
& \bar{D}_{r r}\left(\mathrm{~cm}^{2} / \mathrm{s}\right)=-\frac{350}{D_{c}^{0.8}}+13.0 D_{c}^{0.3} U_{g}^{0.3}
\end{aligned}
$$

The liquid recirculating velocity profile, $\mathrm{u}_{\mathrm{z}}(\mathrm{r})$, is then calculated by the procedure outlined in Figure 2.10, using as input the holdup profile estimated from DP and NDG measurements (Figure 2.8), and the knowledge of the mean recirculation velocity, $\bar{u}_{\text {rec }}$. 


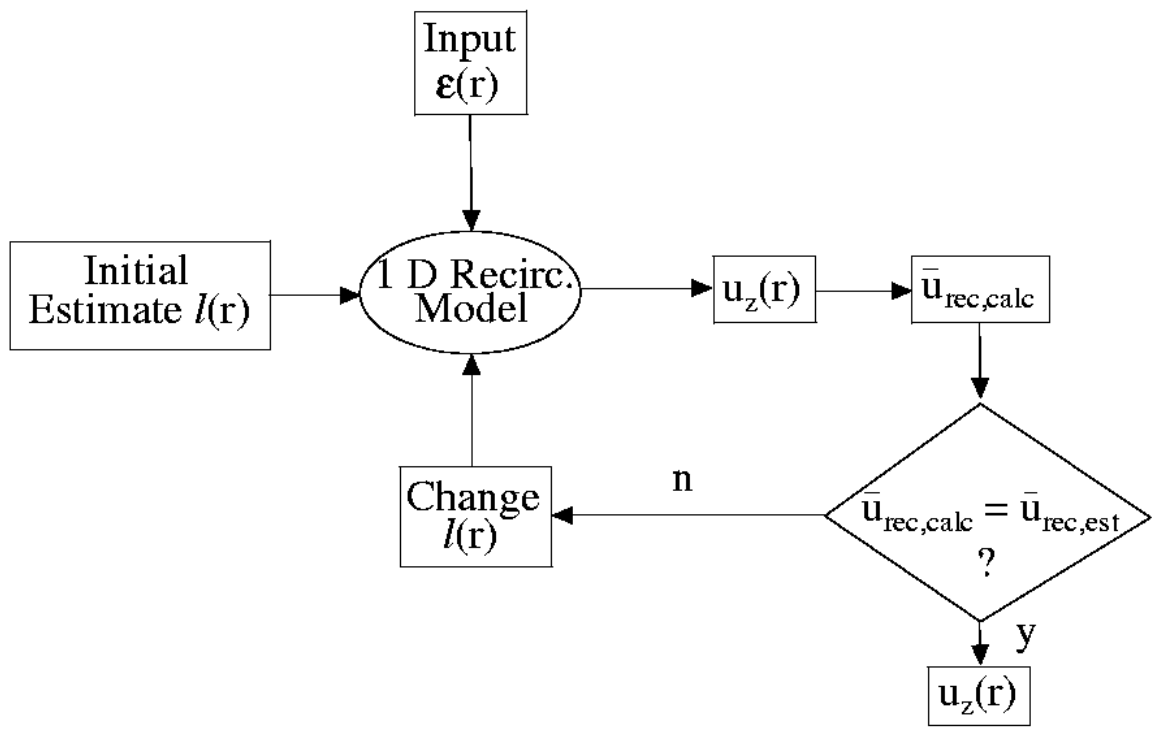

Figure 2.10 Determination of the Liquid Recirculating Velocity Profile, $u_{z}(r)$, with Knowledge of $\varepsilon_{\mathbf{z}}(\xi)$ and $\bar{u}_{r e c}$

The liquid (slurry) recirculation velocity profile evaluated in this manner is shown in Figure 2.11 for Run 14.6.

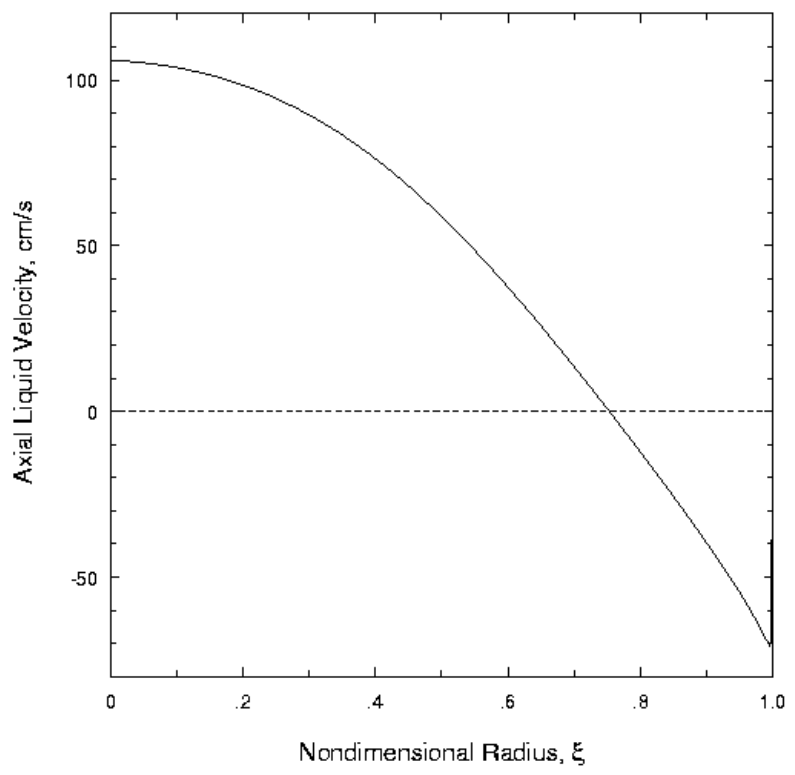

Figure 2.11 Calculated Axial Liquid Velocity Profile for Run 14.6, in the AFDU Reactor During Methanol Synthesis

The centerline velocity calculated is on the order of $1 \mathrm{~m} / \mathrm{s}$. Due to the large area and higher liquid holdup near the wall, the magnitude of the maximum downward liquid velocity is much 
lower than the centerline velocity, in order to satisfy mass balance for the liquid (in batch mode). The radial profiles for the axial and radial eddy diffusivity are calculated from Equations 2.28 and 2.29, respectively, along with the estimated average values (Table 2.3).

$$
\begin{gathered}
\qquad \begin{array}{c}
D_{z z}(\xi)=\bar{D}_{s s} P_{4} \\
\text { where } P_{4}=-3.4979 \xi^{4}+3.2704 \xi^{3}+0.4693 \xi^{2}+0.005035 \xi+0.5847 \\
D_{r r}(\xi)=\bar{D}_{r r} P_{2}
\end{array} \\
\text { where } P_{2}=-5.0929 \xi^{2}+5.0717 \xi+0.1653
\end{gathered}
$$

The profiles for the axial and radial eddy diffusivities, calculated in this manner for Run 14.6, are shown in Figures 2.12 and 2.13, respectively.

Heat exchanger tubes are present in the AFDU reactor for cooling the medium. There are 24 one-inch (O.D.) tubes, which occupy approximately $7.5 \%$ of the cross-sectional area of the reactor, and extend over the entire length of the dispersion. The effect of the heat exchanger tubes is accounted for only with regard to the radial turbulent eddy diffusivity, since the presence of these tubes will physically reduce the radial length scales of turbulence. Liquid recirculation and the axial eddy diffusivity are assumed to be affected to a lesser extent, and for the current calculations, these effects are ignored.

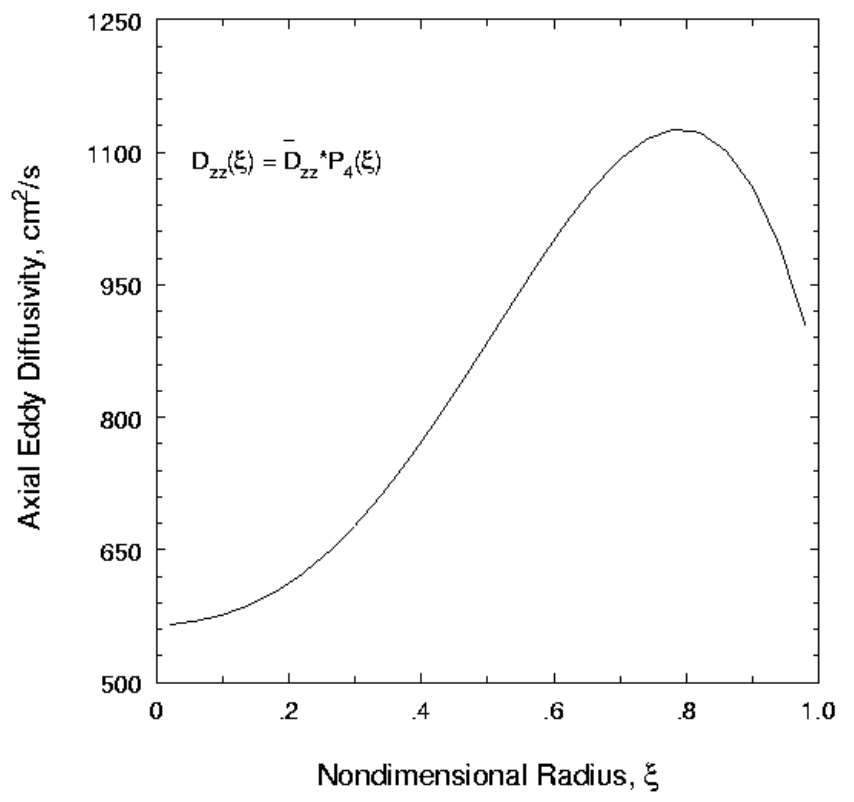

Figure 2.12 Calculated Axial Eddy Diffusivity Profile for Run 14.6, in the AFDU Reactor During Methanol Synthesis 


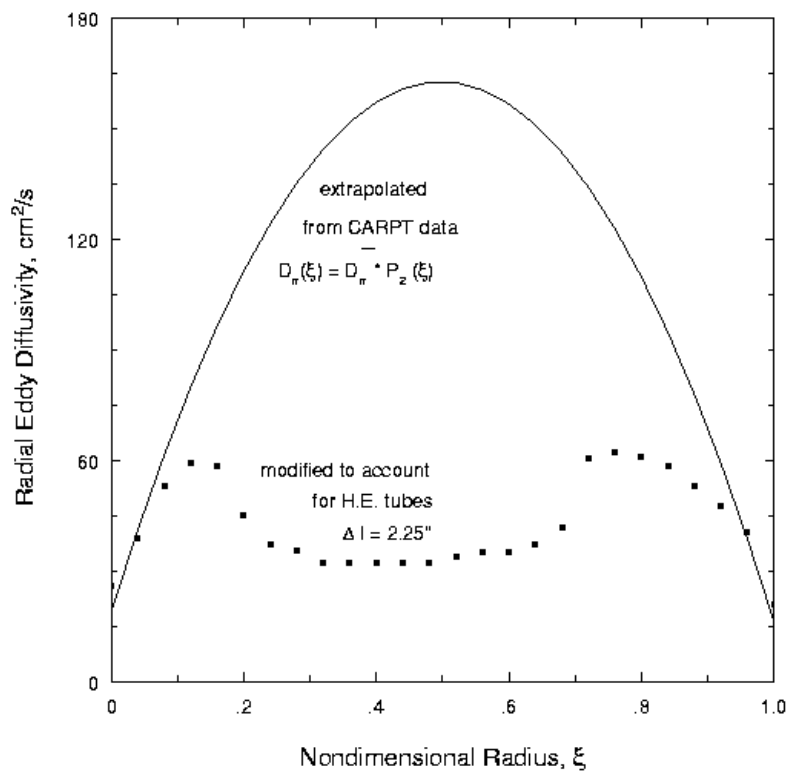

Figure 2.13 Calculated Axial Eddy Diffusivity Profile for Run 14.6, in the AFDU Reactor During Methanol Synthesis

A cross-sectional view of the reactor in the presence of these tubes is shown in Figure 2.14. The tubes are present in two annular rings about the center axis of the reactor, near the region of flow inversion, and will affect the radial turbulent diffusivities in this region by restricting the radial length scale of turbulence. This is accounted for by considering the characteristic spacing between the tubes, which is about 2.25 in. $(5.7 \mathrm{~cm})$, as an effective diameter and estimating the average radial diffusivity for this diameter $(5.7 \mathrm{~cm})$.

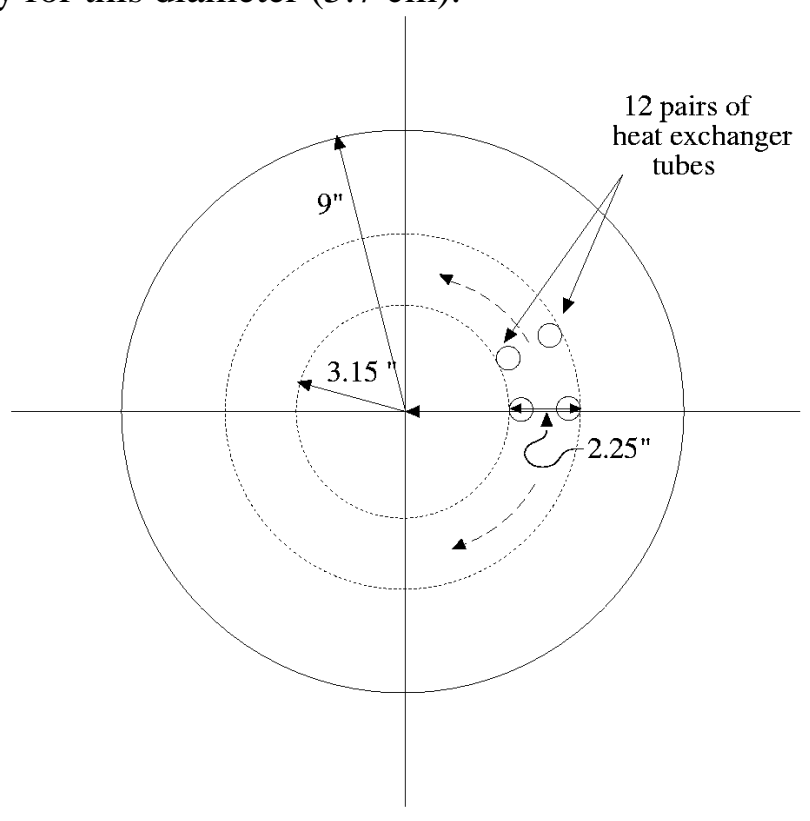

Figure 2.14 Schematic of the Cross-Sectional View of the AFDU Reactor showing Placement of Heat Exchanger Tubes 
Equation 2.27, which was originally developed for large-diameter columns $(>10 \mathrm{~cm})$, is modified by retaining the 0.3 power dependence of $D_{r r}$ on $D_{c}$ and $U_{g}$ (Equation 2.27) for smaller column diameters. With the CARPT data for the $14 \mathrm{~cm}$ diameter column as a reference, the following equation for the radial diffusivity for $\mathrm{D}_{\text {ceff }}=5.7 \mathrm{~cm}$ is used:

$$
\bar{D}_{r r(D c=5.7)}=\left(\frac{5.7}{14.0}\right)^{0.3} \bar{D}_{r r(D c=14)}
$$

The above equation results in a radial diffusivity of $35 \mathrm{~cm}^{2} / \mathrm{s}$. The estimated value of the radial diffusivity in the region of the tubes, results in a modified profile for the radial eddy diffusivity, denoted by the dashed line in Figure 2.13. This represents a first approximation in accounting for the effect of heat exchanger tubes in the AFDU reactor. Thereby, all the input fluid dynamic parameters to the model are evaluated.

\subsubsection{Simulation Results}

The initial and boundary conditions are given below. Since the liquid is in batch mode, zero flux conditions are applied at all the boundaries.

$$
\begin{aligned}
& r=0, r=R ; \quad \frac{\partial C}{\partial r}=0 \\
& z=0, \quad z=L ; \quad \frac{\partial C}{\partial z}=0
\end{aligned}
$$

The initial condition is assigned according to the location of tracer injection during an experiment. In the actual tracer experiment, the injection is made locally at a certain $\left(\mathrm{r}_{\mathrm{i}}, \theta_{\mathrm{i}}, \mathrm{z}_{\mathrm{i}}\right)$. However, since the model is two dimensional, for modeling purposes the injection is considered to be made in an annular ring $\left(\mathrm{r}_{\mathrm{i}}, \mathrm{z}_{\mathrm{i}}\right)$. The initial condition is given as:

$$
\begin{aligned}
& t=0 ; \quad C(r, z, t)=f_{t}(t) \quad r=r_{i}, z=z_{i} \\
& =0 \quad r \neq r_{i}, z \neq z_{i}
\end{aligned}
$$

$\mathrm{f}_{\mathrm{t}}(\mathrm{t})$ describes the pulse of tracer injected (close to an impulse function), and is fitted to the response of the detector close to the location of injection. For a given experimental condition, four tracer experiments were carried out with four different locations of the injection point. These are provided in Table $2.2\left(r_{i}\right.$ and $z_{i}$ are given in $\left.\mathrm{cm}\right)$.

Table 2.2 Positions of Tracer Injection in the Model

\begin{tabular}{|c|c|c|}
\hline & $r_{i}(\mathrm{~cm})$ & $z_{i}(\mathrm{~cm})$ \\
\hline Wall injection at N1 & 22.8 & 966.0 \\
Center injection at N1 & 11.5 & 966.0 \\
Wall injection at N2 & 22.8 & 356.0 \\
Center injection at N2 & 11.5 & 356.0 \\
\hline
\end{tabular}


In order to compare the experimental results with model predictions, the individual detector responses measured by the four detectors at each axial level are averaged to yield an averaged detector response at each detector level. Averaging is done since the current model is only two dimensional, and cannot distinguish any angular variations in tracer concentration. Responses of the individual detectors at two axial levels indicate that such an (angular) averaging of the four detector responses at a given axial location is a reasonable approximation. The averaged experimental detector responses measured at the seven detector levels, for the wall injection at level N1 in Run 14.6, are shown in Figure 2.15. It is to be noted that the various detector level responses do not all show equal measurements at the end of long periods, which is what is expected if the tracer is eventually uniformly distributed in the reactor. Improper normalization of the detector responses caused this lack of uniformity. Specific details and reasons for this are shown elsewhere (Degaleesan, 1997), where suggestions have been made to improve the quality of the tracer data. Due to this lack of uniformity, the experimental detector responses cannot be quantitatively compared with the model predictions of the tracer distribution in the column. Only the characteristic mixing times as measured by the times of the peaks of the curves can be compared.

The radiation intensity emitted per unit volume by the tracer is directly proportional to the tracer concentration. Since the experiments involve radioactive tracer, the measurements, as detected by the scintillation detectors, represent neither local nor average tracer concentration, but the attenuated cumulative tracer concentration in a given cross-sectional plane.

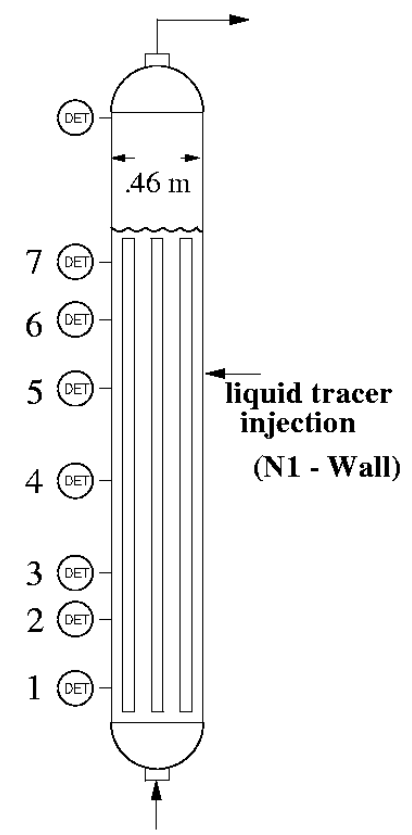

Figure 2.15 (a) Position of Liquid Tracer Injection to Wall of Reactor for Tracer Experiments 


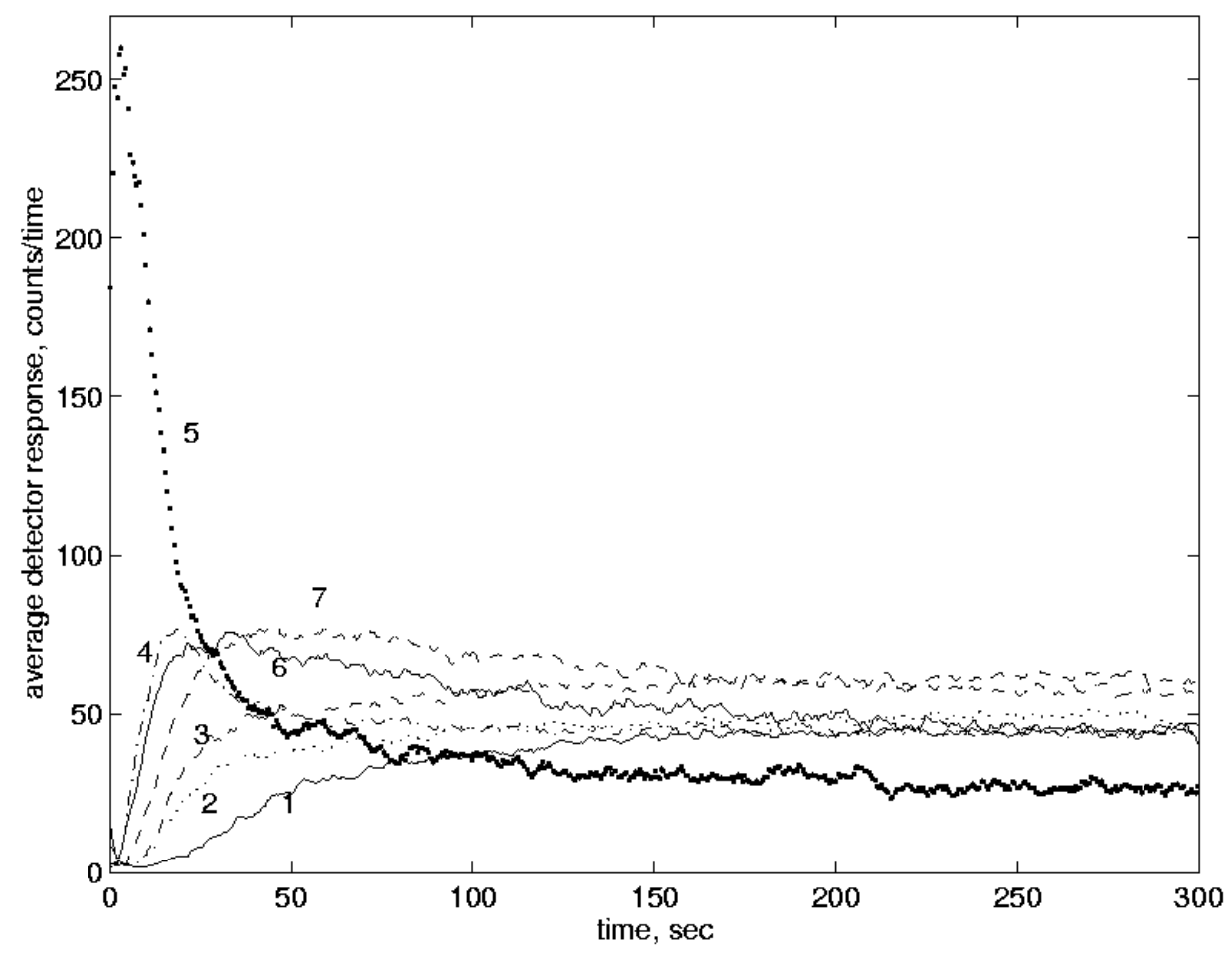

Figure 2.15 (b) Experimental Detector Responses for Wall Injection at Level N1 for Run 14.6

The detectors are shielded on their sides. Hence, most of the radiation detected emanates from the cross-sectional plane at the axial level of the detector. In order to compare the model predictions with the averaged experimental detector response, the local tracer concentration in a two-dimensional axisymmetric domain, $C(r, z, t)$, is first integrated along the radial path $r$ through the column center, using the Beer-Lambert law, to yield a representative radioactive tracer response at a given axial location, $\breve{C}(z, t)$. Therefore,

$$
\left.\breve{C}(z, t)=\int_{r^{\prime}=0}^{r^{\prime}=R} C\left(r^{\prime}, z, t\right) \exp \left(-\int_{r^{\prime}}^{R} \mu_{e f f}\left(r^{\prime \prime}\right) d r^{\prime \prime}\right) d r^{\prime}\right)
$$

where

$$
\mu_{e f f}(r)=\mu_{g} \varepsilon_{g}(r)+\mu_{s l} \varepsilon_{s l}(r)
$$

$\breve{C}(z, t)$ represents the response measured by the shielded and collimated detectors, which have been used for the current experiments. Since the detectors are collimated, the only significant contribution of the radiation that is measured emanates from the tracer along the radial path $r$ through the column center. Hence, the contribution from the angular and axial direction is ignored in the calculations. The $M n^{56}$ particles emit $\gamma$ radiation at $0.85 \mathrm{MeV}$. The catalyst loading in the reactor for all three runs was kept at a constant of $40 \%$ by weight. For a given 
composition of the catalyst particles resulting in a bulk density $\rho_{\mathrm{s}}=2.02 \mathrm{gm} / \mathrm{cm}^{3}$, and liquid (hydrocarbon oil) density of $\rho_{1}=0.667 \mathrm{gm} / \mathrm{cm}^{3}$, the linear attenuation coefficient of the slurry at $0.85 \mathrm{MeV}$ is $\mu_{\mathrm{sl}}=0.06728 \mathrm{~cm}^{-1}$, and for the gas it is $\mu_{\mathrm{g}}=1.0 \mathrm{e}-5 \mathrm{~cm}^{-1}$.

Figures 2.16 and 2.17 compare model predictions with the experimental tracer responses for the wall injection at level N1 for Run 14.6. The calculated as well as the measured responses have been normalized with respect to their maximum for the sake of comparison. The results show that the model is able to capture the characteristic overshoots as seen by the detector responses at all the measurement levels. A quantitative comparison of the tracer responses is unfortunately not possible due to the fact that the experimental data do not level off at the end of long periods at the same height for all the detectors.

Figures 2.18 and 2.19 compare model predictions and experimental detector responses for the center injection at level N2, and Figure 2.20 compares them at level N1 (Figure 2.9). Experimental data at Levels 5, 6 and 7 for center injection at $\mathrm{N} 1$ and at all levels for the wall injection at N2 in Run 14.6 were not available for comparison. For all the different locations of injection, since the operating process conditions are the same, the input model parameters are fixed. Therefore, with a consistent set of model parameters, the model is able to capture the internal liquid (slurry) and overall mixing in the AFDU reactor, as measured by the detector responses at all seven locations. Table 2.3 lists the average input parameters calculated for all three experimental conditions considered. The radial profiles for liquid velocity and turbulent diffusivities were obtained using the developed scaleup procedure. 
(a) Detector level 1

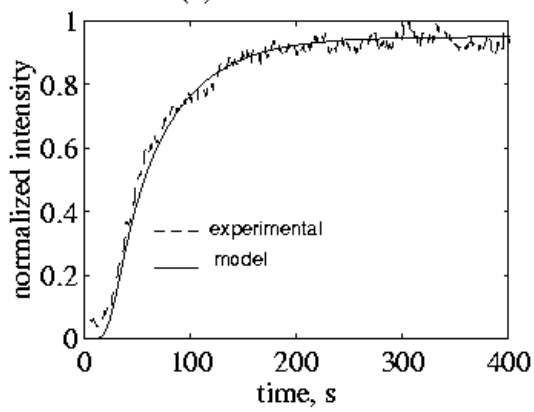

(c) Detector level 3

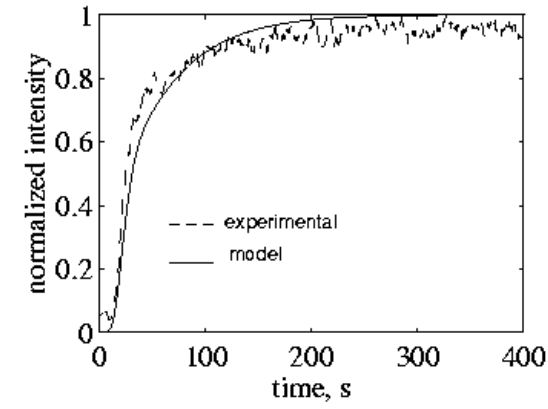

(b) Detector level 2

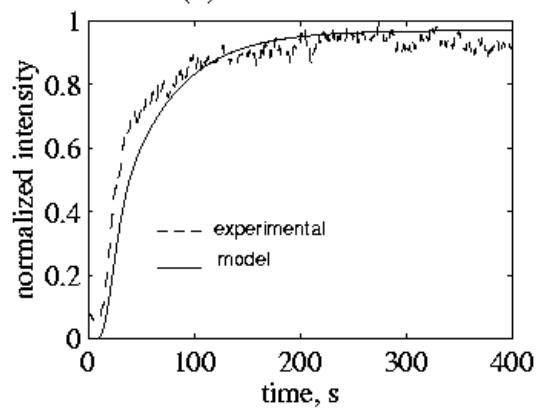

(d) Detector level 4

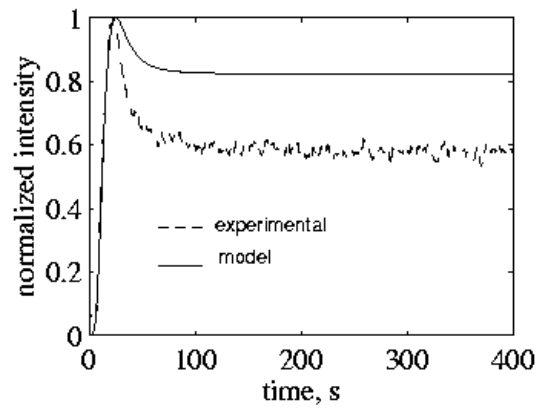

Figure 2.16 Comparison of Model Prediction with Experimental Detector Responses for Wall Injection at Level N1, Run 14.6 
(e) Detector level 5

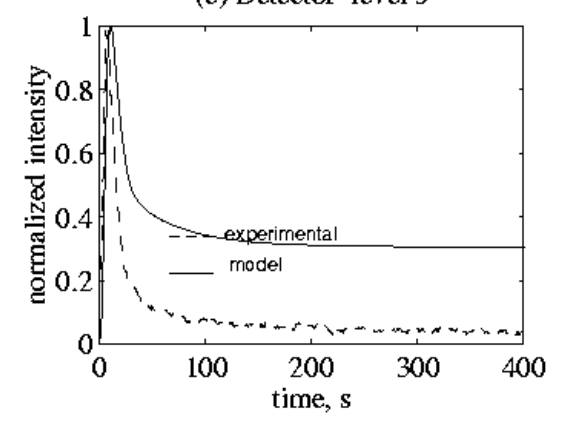

(f) Detector level 6

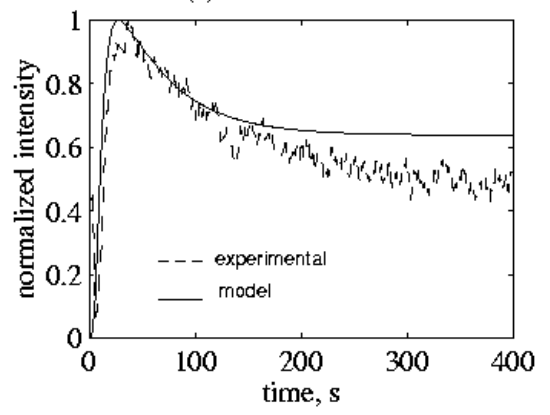

(g) Detector level 7

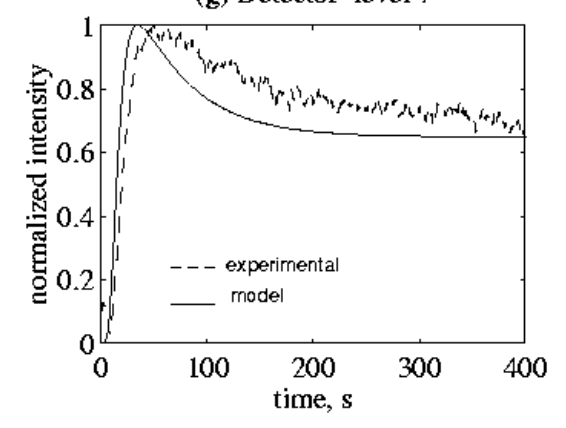

Figure 2.17 Comparison of Model Prediction with Experimental Detector Responses for Wall Injection at Level N1, Run 14.6 
(a) Detector level 1

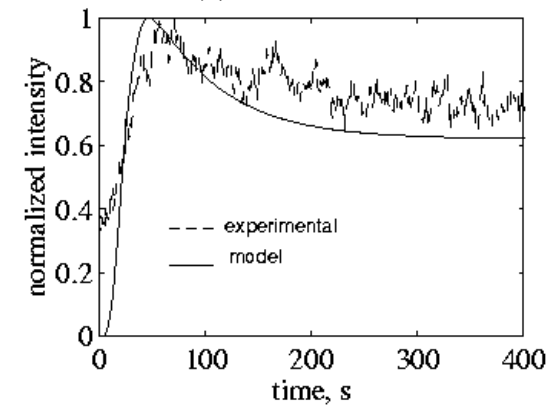

(c) Detector level 3

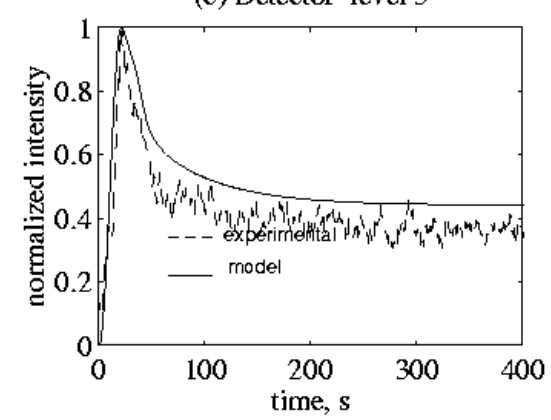

(b) Detector level 2

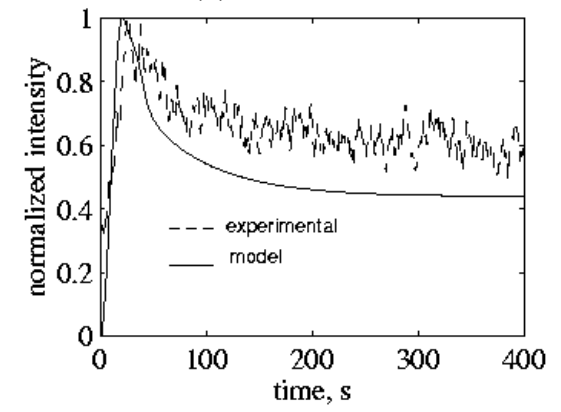

(d) Detector level 4

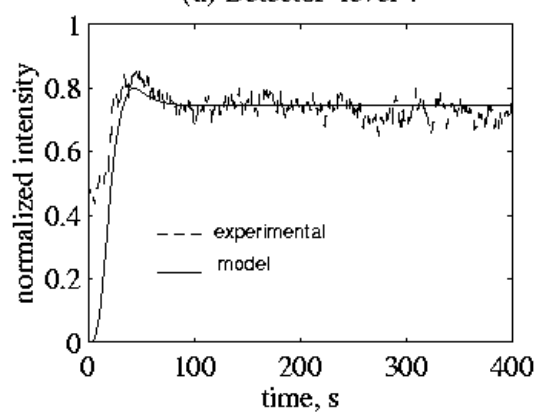

Figure 2.18 Comparison of Model Prediction with Experimental Detector Responses for Center Injection at Level N2, Run 14.6 
(e) Detector level 5

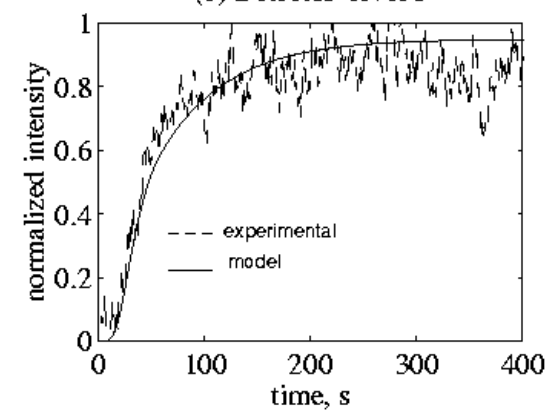

(f) Detector level 6

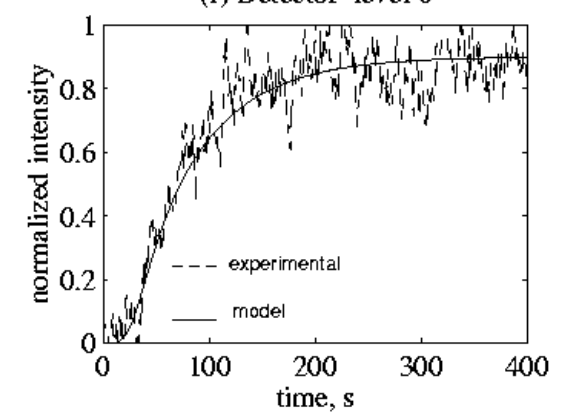

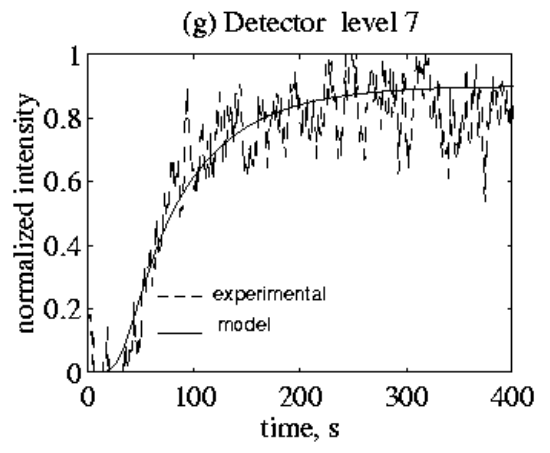

Figure 2.19 Comparison of Model Prediction with Experimental Detector Responses for Center Injection at Level N2, Run 14.6 
(a) Detector level 1

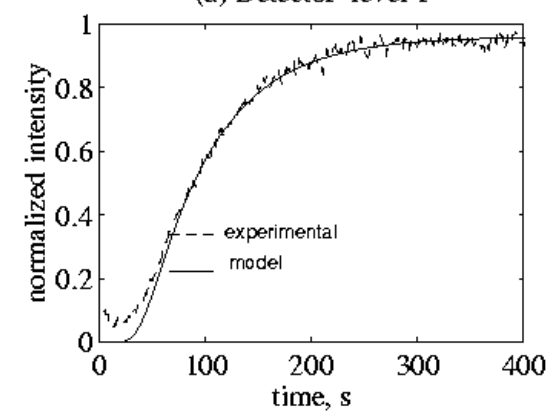

(c) Detector level 3

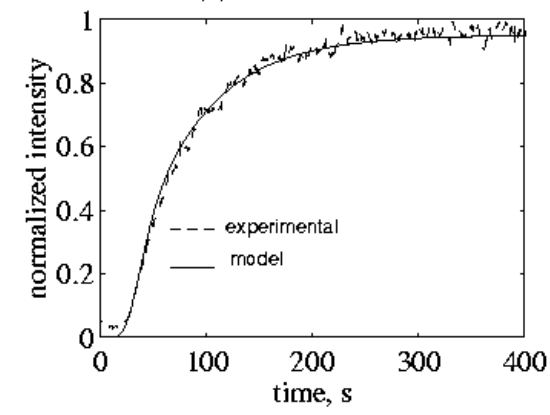

(b) Detector level 2

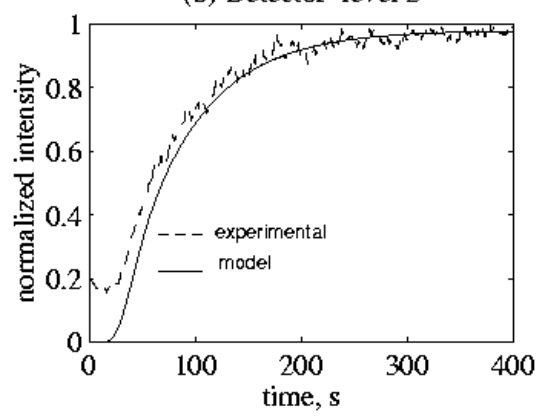

(d) Detector level 4

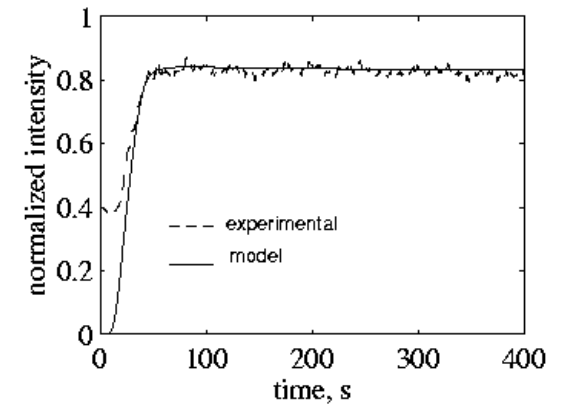

Figure 2.20 Comparison of Model Prediction with Experimental Detector Responses for Center Injection at Level N1, Run 14.6 


\section{Table 2.3 List of Estimated Average Fluid Dynamic Parameters for the LaPorte AFDU during Methanol Synthesis}

\begin{tabular}{|c|c|c|c|c|c|c|}
\hline Run No. & $\begin{array}{c}U_{g 0} \\
\mathrm{~cm} / \mathrm{s}\end{array}$ & $\bar{\varepsilon}_{g}$ & $\begin{array}{c}U_{g e} \\
\mathrm{~cm} / \mathrm{s}\end{array}$ & $\begin{array}{c}\bar{u}_{r e c} \\
\mathrm{~cm} / \mathrm{s}\end{array}$ & $\begin{array}{c}\bar{D}_{z z} \\
\mathrm{~cm}^{2} / \mathrm{s}\end{array}$ & $\begin{array}{c}\bar{D}_{r r} \\
\mathrm{~cm}^{2} / \mathrm{s}\end{array}$ \\
\hline 14.6 & 25.0 & 0.39 & 47.4 & 47.6 & 965.2 & 114.1 \\
14.7 & 14.0 & 0.33 & 33.1 & 41.2 & 854.0 & 100.7 \\
14.8 & 36.0 & 0.38 & 44.7 & 46.5 & 946.0 & 111.3 \\
\hline
\end{tabular}

It should be noted that while Runs 14.6 and 14.7 were at a higher pressure of $52 \mathrm{~atm}$, Run 14.8, which was carried out at a higher superficial gas velocity of $36 \mathrm{~cm} / \mathrm{s}$, was at a lower pressure of $36 \mathrm{~atm}$. The effect of pressure is evident in the gas holdup measurements, which indicate a lower holdup for Run 14.8 in comparison with Run 14.6, although it was operated at a higher superficial gas velocity.

The results of the model predictions for the various injections of Runs 14.7 and 14.8 are shown elsewhere (Degaleesan, 1997). It is clear from these figures that the model is, in general, able to correctly predict the mixing patterns within the reactor shown by the detector responses. By using a single set of input parameters (Table 2.3) for a given experimental condition, the model is able to capture the mixing patterns for the various injection locations, as measured by detectors at all levels. This substantiates using the proposed convective-diffusion model to describe liquid mixing based on liquid recirculation and turbulence, and suggests that the preliminary scaleup rules developed result in a good estimate of the input fluid dynamic model parameters. Such comparisons indirectly justify the proposed methodology of characterization of churn-turbulent bubble columns by using the gas holdup in the reactor as a means of accounting for the effects of pressure, solids and other system parameters.

The approach used for evaluation of the model parameters stresses the importance of measurement and prediction of the gas holdup and its radial distribution in the column. Several correlations exist in the literature that account for the effects of pressure and liquid properties on overall gas holdup. However, there is no good agreement between the correlations, even at atmospheric pressure. Table 2.4 shows the correlations used to estimate the transition holdup and transition gas velocity based on the bimodal bubble size distribution in churn-turbulent flow. Measurements of large bubble holdup and rise velocities, using dynamic gas disengagement (DGD) under different process conditions, have resulted in correlations listed in Table 2.5.

A combination of the correlations of Wilkinson et al. (1992) for the transition holdup and velocity (1T. in Table 2.4), along with that of Krishna and Ellenberger (1996) for the dilute phase holdup (2L. in Table 2.5), seems to yield the best estimates for the global gas holdup compared to experimental data in the AFDU during methanol synthesis (Table 2.1). The slurry phase properties existing under experimental conditions in the AFDU are considered, instead of the liquid (except for the surface tension, $\sigma$, since no data were available for the slurry), resulting in gas holdups reported in Table 2.6. The estimated values of the overall gas holdup show 
Table 2.4 Correlations for Estimating the Transition Holdup and Transition Gas Velocity based on the Bimodal Bubble Size Distribution in Churn-Turbulent Flow (SI units)

\begin{tabular}{|c|c|c|}
\hline No. & Reference & \\
\hline $1 \mathrm{~T}$. & $\begin{array}{l}\text { Wilkinson et al. } \\
\text { (1992) }\end{array}$ & $\begin{array}{l}\varepsilon_{\text {trans }}=0.5 \exp \left(-193 \rho_{g}^{-0.61} \mu_{l}^{0.5} \sigma^{0.11}\right) \\
\frac{V_{\text {small }} \mu_{l}}{\sigma}=2.25\left(\frac{\mu_{l}^{4} g}{\rho_{l} \sigma^{3}}\right)^{0.273}\left(\frac{\rho_{l}}{\rho_{g}}\right)^{0.03} \\
U_{\text {trans }}=\varepsilon_{\text {trans }} V_{\text {small }}\end{array}$ \\
\hline $2 \mathrm{~T}$. & Reilly et al. (1994) & $\begin{aligned} \varepsilon_{\text {trans }} & =4.457 \sqrt{\frac{\rho_{g}^{0.96}}{\rho_{l}} \sigma^{0.12}} \\
V_{\text {small }} & =\frac{1}{2.84} \frac{1}{\rho_{g}^{0.04}} \sigma^{0.12} \\
U_{\text {trans }} & =\varepsilon_{\text {trans }} V_{\text {small }}\left(1-\varepsilon_{\text {trans }}\right)\end{aligned}$ \\
\hline
\end{tabular}

Table 2.5 Correlations for Estimating the Large Bubble Holdup and Overall Holdup based on the Bimodal Bubble Size Distribution in Churn-Turbulent Flow (SI units)

\begin{tabular}{|c|c|l|l|}
\hline No. & Ref. & & \\
\hline 1L. & $\begin{array}{c}\text { Wilkinson } \\
\text { et al. } \\
(1992)\end{array}$ & $\frac{V_{l b} \mu_{l}}{\sigma}=\frac{V_{\text {small }} \mu_{l}}{\sigma}+$ & \\
& $2.4\left[\frac{\left(U_{g}-U_{\text {trans }}\right) \mu_{l}}{\sigma}\right]^{0.757}\left(\frac{\mu_{l}^{4} g}{\rho_{l} \sigma^{3}}\right)^{0.077}\left(\frac{\rho_{l}}{\rho_{g}}\right)^{0.077}$ & $\bar{\varepsilon}_{g}=\varepsilon_{\text {trans }}+\varepsilon_{l b}$ \\
\hline 2L. & $\begin{array}{c}\text { Krishna et } \\
\text { al. (1996) }\end{array}$ & $\varepsilon_{l b}=\frac{\left(U_{g}-U_{\text {trans }}\right)}{V_{l b}}$ & $\bar{\varepsilon}_{g}=\varepsilon_{l b}+$ \\
$D_{c}^{0.18}\left(U_{g}-U_{\text {trans }}\right)^{0.58}$ & $\varepsilon_{\text {trans }}\left(1-\varepsilon_{l b}\right)$ \\
\hline
\end{tabular}


reasonable agreement with the measured average holdup, especially at the two higher gas velocities. However, the estimated transition gas velocity from bubbly flow to churn-turbulent flow seems low when compared with experimental results for atmospheric air-water systems. This is partly due to the high values of the holdup of the small bubbles. The high holdup of small bubbles (transition holdup), which is the same for Runs 14.6 and 14.7, results in a higher value of the gas holdup for Run $14.7\left(U_{g}=14.0 \mathrm{~cm} / \mathrm{s}\right)$, compared with experimental measurements.

The correlations of Wilkinson et al. (1992) yield much higher values for the large bubble holdup (1L. in Table 2.5). This may be caused by the fact that his correlation does not take into consideration the effect of column diameter on large bubble holdup (which is supposed to decrease with increase in column diameter). Reilly's correlation (2T. in Table 2.4), which resulted in moderate estimates of the transition gas velocity and holdup under atmospheric conditions, greatly overpredicts the transition holdup for the current high-pressure data. For example, for Run 14.6, the transition holdup calculated from Reilly's correlation gives $\varepsilon_{\text {trans }}=$ 0.58 , which is much higher than the overall gas holdup measured in the reactor, $\sim 0.4$. This points to the disparity in the available correlations, which perform well only under a certain range of operating and process conditions.

Table 2.6 Estimation of Global Gas Holdup in the Reactor Using Correlations from the Literature

\begin{tabular}{|c|c|c|c|c|c|c|c|}
\hline \multirow{2}{*}{$\begin{array}{l}\text { Run } \\
\text { No. }\end{array}$} & \multirow{2}{*}{$\begin{array}{c}U_{g 0} \\
\mathrm{~cm} / \mathrm{s}\end{array}$} & \multirow{2}{*}{$\begin{array}{c}\text { Press. } \\
\mathrm{MPa}\end{array}$} & \multicolumn{2}{|c|}{ Wilkinson (1992) } & \multicolumn{2}{|c|}{ Krishna et al. 1996} & \multirow{2}{*}{$\begin{array}{c}\text { Measured } \\
\bar{\varepsilon}_{g} \\
\end{array}$} \\
\hline & & & $\varepsilon_{\text {trans }}$ & $\mathrm{U}_{\text {trans }}(\mathrm{m} / \mathrm{s})$ & $\varepsilon_{\mathrm{lb}}$ & $\bar{\varepsilon}_{g}$ & \\
\hline 14.6 & 25.0 & 5.2 & 0.28 & 0.056 & 0.120 & 0.40 & 0.39 \\
\hline 14.7 & 14.0 & 5.2 & 0.28 & 0.056 & 0.073 & 0.35 & 0.33 \\
\hline 14.8 & 36.0 & 3.6 & 0.24 & 0.049 & 0.160 & 0.40 & 0.38 \\
\hline
\end{tabular}

Correlations such as those presented above are useful in estimating the global gas holdup. There is still no way (empirical or theoretical) to predict the holdup profiles in the reactor. For such situations, global holdup measurements from DP and NDG prove to be helpful in calculating the gas holdup profile, as discussed earlier.

\subsection{Summary}

The two-dimensional axisymmetric convection-diffusion model provides a good representation of internal liquid mixing in bubble columns. The instantaneous flow in bubble columns is highly turbulent and transient in nature, and the time-averaged velocity profile does not exist in the column at any instant in time; however, by properly accounting for the churn-turbulent flow via the turbulent eddy diffusivities, the model is able to statistically capture the large-scale transient flow patterns in the column, thereby yielding the characteristic overshoots seen by the detectors at various axial locations. This represents the meso-scale and macro-scale mixing in the column, which is of importance for modeling bubble column reactors. Results also imply that CARPT measurements for the turbulent eddy diffusivities can provide suitable closure for the $\left\langle\vec{u}^{\prime} C^{\prime}\right\rangle^{x}$ terms appearing in the original balance equations. Such model predictions for liquid mixing in 
bubble columns are the first of their kind, and are truly "predictions," involving no fitting parameters. The developed model, along with experimental input for the model parameters, therefore allows us to study the influence of fluid dynamics on liquid mixing in bubble columns.

The developed scaleup strategy reported in the $12^{\text {th }}$ and $13^{\text {th }}$ quarterly reports (Degaleesan, 1997) for evaluating the model parameters in the AFDU slurry bubble column reactor during methanol synthesis, results in fairly good predictions of the characteristic mixing times within the column as measured by the radiation detectors at various axial locations. This indirectly substantiates the proposed methodology of using the gas holdup in churn-turbulent flows, at sufficiently high gas velocities, to characterize the systems of interest.

\subsection{References}

Degaleesan, S., M. P. Dudukovic, B. A. Toseland and B. L. Bhatt, "Tracer Studies of the LaPorte AFDU Reactor During Methanol Synthesis," Fourth Quarterly Report, DOE Contract DE-FC 2298 PC 95051 (1996b).

Degaleesan, S., "Fluid Dynamic Measurements and Modeling of Liquid Mixing in Bubble Columns,” D.Sc. Thesis, Washington University, St. Louis, MO (1997).

Hinze, J. O., “Turbulence,” McGraw-Hill, New York (1975).

Krishna, R., and J. Ellenberger, "Gas Holdup in Bubble Column Reactors Operating in the Churn-Turbulent Flow Regime,” AIChE J., Vol. 42, 2627-2634 (1996).

Myers, K. J., M. P. Dudukovic, and P. A. Ramachandran, "Modeling of Churn-Turbulent Bubble Columns - I: Liquid Phase Mixing," Chem. Eng. Sci., Vol. 42, 2301-2311 (1986).

Patankar, S. V., "Numerical Heat Transfer and Fluid Flow," Hemisphere Publishing Corporation, New York (1980).

Reilly, I. G., D. S. Scott, T .J. W. de Bruin, and D. MacIntyre, "The Role of Gas Momentum in Determining Gas Holdup and Hydrodynamic Flow Regimes in Bubble Column Operations," Can. J. Chem. Eng., Vol. 72, 3-12 (1994).

Seinfeld, J. H., “Atmospheric Chemistry and Physics of Air Pollution," Wiley Publications, New York (1986).

Shollenberger, K. A., and T. J. O'Hern, Report entitled "Hydrodynamic Characterization of Slurry-Phase Flow in the LaPorte Alternative Fuels Development Unit (AFDU) Using Differential Pressure Measurements," Sandia National Laboratories (1995b).

Tennekes, H., and J. L. Lumley, “A First Course on Turbulence,” The MIT Press, Cambridge (1972). 
Verstaag, H. K., and W. Malalasekera, "An Introduction to Computational Fluid Dynamics - The Finite Volume Method," Longman Scientific and Technical, John Wiley and Sons, New York (1995).

Wilkinson, P. M., A. P. Spek, and L. L. van Dierendonck, "Design Parameters Estimation for Scaleup of High-Pressure Bubble Columns,” AIChE J., Vol. 38, 544-554 (1992). 